\title{
Effects of Microbiological and Physicochemical Properties of Cow's Milk and Goat's Milk Dadih Inoculated with Various Lactobacillus Species
}

\author{
Mohd Nizam Lani ${ }^{a, b, *}$, Nurshafika Bahara, Elham Taghavi ${ }^{a}$, Fauziah Tufail \\ Ahmad $^{a}$, S.A. Sharifudinc, Wan Mohd Arif Aziz Japard \\ a Faculty of Fisheries and Food Science, Universiti Malaysia Terengganu, 21030, \\ Kuala Nerus, Terengganu, Malaysia; ${ }^{b}$ Institute of Marine Biotechnology, Universiti \\ Malaysia Terengganu, 21030, Kuala Nerus, Terengganu, Malaysia; ' Enzyme and \\ Fermentation Technology Programme, Food Science and Technology Research \\ Centre, MARDI Headquarters, 43400 Serdang, Selangor, Malaysia; ${ }^{d}$ Malaysia - \\ Japan International Institute of Technology (MJIIT), Universiti Teknologi Malaysia \\ Kuala Lumpur, Jalan Sultan Yahya Petra, 54100 Kuala Lumpur, Malaysia
}

Abstract Dadih is a dairy-based product and it is one of the most popular desserts among Malaysians and Indonesians. It is made from raw milk which naturally contains various types of microorganisms. This study was conducted to develop cultured dadih by inoculating various Lactobacillus species such as Lactobacillus acidophilus, Lactobacillus plantarum and Lactobacillus paracasei into dadih made from cow's milk and goat's milk. Prior to isolation of LAB from control dadih (dadih without inoculation with $L A B$ ), the dadih was stored at $4^{\circ} \mathrm{C}$ for 48 hours. The microbiological (general microbial load, viability of and $L A B$, mould and yeast count) and physicochemical properties $\mathrm{pH}$, lactic acid content, total soluble solid, colour, texture and proximate composition) of dadih with different LAB strains and without LAB strain were determined. Results showed that $L$. paracasei spp. paracasei, Lactobacillus brevis, Lactobacillus casei were isolated from cow's milk dadih while only $L$. paracasei spp. paracasei was isolated from goat's milk dadih. The number of LAB ranged from 5.73 to $6.06 \log _{10} \mathrm{CFU} / \mathrm{g}$ for cow's milk dadih and 5.19 to $5.88 \log _{10} \mathrm{CFU} / \mathrm{g}$ for goat's milk dadih. Results revealed that dadih inoculated with $\mathrm{LAB}$ has lower $\mathrm{pH}$ and greater amount of lactic acid produced than control dadih. Total soluble solid for dadih with $L A B$ also decreased. Hardness of dadih without $L A B$ culture was higher compared to the inoculated dadih with LAB cultures. Proximate compositions (moisture,

*For correspondence: nizamlani@umt.edu.my

Received: 7 April 2021 Accepted: 23 Nov 2021

(C) Copyright Lani et al. This article is distributed under the terms of the Creative Commons Attribution License, which permits unrestricted use and redistribution provided that the original author and source are credited. ash, crude fat, crude protein and total carbohydrate) showed variations due to differential formulations and incorporations of different LAB strains. Findings showed that $L$. acidophilus was chosen as the best starter culture for both types of dadih because it has significant effects on $\mathrm{pH}$, titratable acidity, total soluble solid and texture of the dadih.

Keywords: Dadih, probiotic, Lactobacillus, cow's milk, goat's milk, starter cultures.

\section{Introduction}

Today, the food market in South-East Asia is flooded with a variety of dairy products such as yogurt, cheese and dadih. Dadih is one of the most popular traditional desserts among Malaysians and Indonesians due to its appealing sweet taste and jelly-like appearance [1]. Generally, it is made either 
from cow's milk or buffalo's milk. Naturally, milk is rich in nutrients and contain diverse microflora. However, native microorganisms especially heat-sensitive bacteria might be killed during dadih preparation due to high heat applied [1].

Dairy products, as well as fermented dairy products, have been enhanced with health beneficiary elements and designated as functional foods for the consumers [2]. Incorporation of potential probiotic microorganisms is one of the ways to improve product quality and this may attract consumers who are concerned with healthy food.

Lactic Acid Bacteria $(L A B)$ is a group of Gram-positive, non-spore forming, coccus or rod-shaped bacteria. Probiotic bacteria, mainly LAB, give benefits to consumer health by maintaining or improving their intestinal microbial balance [1]. Probiotics are microorganisms that have beneficial effects on the intestinal functions and can promote good health. Besides, they are able to ferment carbohydrates and produce lactic acid or a mixture of lactic acid, carbon dioxide and acetic acid or ethanol. Moreover, other compounds such as diacetyl, acetaldehyde and hydrogen peroxide are also produced during fermentation. These compounds contribute to the flavour and texture of fermented foods and they help in the inhibition of undesirable microbes [3].

Previously, there were several studies that have been conducted on dadih. Based on previous studies by Yuliana et al. [4], lactic acid bacteria isolated from buffalo dadih produced bacteriocin which has antimicrobial properties. In other study by Venema and Surono [5], microbiota composition of dadih from different producers in West Sumatra, Indonesia were determined. Other study also showed that the traditional Indonesian dadih can be used as potential sources of probiotics as they commonly contain LAB, including species of Lactobacillus, Pediococcus, Enterococcus, Weisella and Leuconostoc [3]. Besides, based on previous studies, the incorporation of a source of prebiotic affects the viability of Lactobacillus acidophilus FTDC 1295 and the chemical composition of dadih samples [2]. The finding showed that the probiotic viability was maintained at a high number of LAB which is more than $8 \log _{10}$ CFU/g throughout storage [2].

To produce a new dairy-based product such as cultured dadih, safety of the product is very crucial [1]. Safety and physicochemical analysis need to be conducted in order to predict the stability and product quality of the cultured dadih. Due to the increase in demand from consumers for healthy food products that contain probiotics, therefore, this study was conducted to determine the effect of different sources of milk on microbiological and physicochemical properties of dadih with different commercial stains of LAB.

\section{Materials and methods}

\section{Milk Samples}

Fresh cow's milk and goat's milk were used in this study. The fresh cow's milk samples were collected from Bukit Payong, Terengganu while the fresh goat's milk samples were collected from Goat Farm Petai Bubus in Manir, Terengganu. The samples were stored in chiller at $5^{\circ} \mathrm{C}$ at Food Processing Laboratory, Faculty of Fisheries and Food Science, University Malaysia Terengganu.

\section{Source of Microorganisms}

The lactic acid bacteria (LAB), namely Lactobacillus plantarum, Lactobacillus acidophilus and Lactobacillus paracasei used in this study were obtained through the courtesy of MARDI Research Centre Serdang, Malaysia. These cultures were in the form of freeze-dried and purchased from the probiotic company, UAS Laboratories, United States of America, where this company is one of few fully integrated suppliers of probiotic solutions (http://www.uaslab.com). These cultures were used as starter culture in dadih production. The LAB were inoculated into the dadih and the effects of the LAB on the microbiological and physicochemical properties of dadih were observed.

\section{Culture Media}

The media used in this study were de Man, Rogosa and Sharpe (MRS) agar, MRS agar supplemented 
with $0.8 \% \mathrm{CaCO}_{3}$, MRS broth, nutrient agar, plate count agar and potato dextrose agar for the isolation of LAB, LAB count, Total Plate Count and Yeast and Mould Count, accordingly. All microbiological media and broth were purchased from Merck, Germany. The media were prepared and sterilised using an autoclave (Hiramaya HVE-50, Japan) as specified on the manufacturer's directions. The prepared agars were poured in sterile Petri dishes, left and cooled before they were used for the analysis.

\section{Preparation of Inoculum}

Each strain of LAB was cultured in $10 \mathrm{ml}$ of de Man, Rogosa and Sharpe (MRS) broth and incubated at $30^{\circ} \mathrm{C}$ for 24 hours [1]. Then, each culture of bacteria was streaked on MRS agar and incubated at $30^{\circ} \mathrm{C}$ for 48 hours. 10 single colonies were inoculated into $100 \mathrm{ml}$ of MRS broth and incubated in $\mathrm{CO}_{2}$ incubator at $30^{\circ} \mathrm{C}$ for 24 hours anaerobically. Then, $10 \mathrm{ml}$ of incubated broth was centrifuged at $4000 \mathrm{rpm}$ for 10 minutes using the centrifuge (Gryozen, Korea). The pellet and supernatant produced from the centrifugation and the supernatant were discarded from the pellet. Next, the pellet was washed using $0.1 \%$ phosphate buffered saline (PBS) twice. Then, it was resuspended in $10 \mathrm{ml}$ of $0.1 \%$ of PBS in order to obtain inoculum. The freshly prepared inoculum was inoculated in the dadih at $40^{\circ} \mathrm{C}$. All steps were carried out aseptically.

\section{Preparation of Dadih}

Dadih was prepared in the Food Processing Laboratory, Faculty of Fisheries and Food Science, UMT. A thousand $\mathrm{ml}$ of milk was heated in the saucepan. Then, $100 \mathrm{~g}$ of dadih powder and $100 \mathrm{~g}$ of sugar were added into the milk and were stirred. After reaching $85^{\circ} \mathrm{C}$, the heat was turned off and the dadih was dispensed into $50 \mathrm{ml}$ sterilised plastic cups. Then, the inoculum was inoculated into the dadih aseptically when the temperature of the dadih reached $40^{\circ} \mathrm{C}$ and the cups were labelled [1]. However, the starter culture was not added in the control dadih. Then, all dadih samples were stored in a chiller at $4^{\circ} \mathrm{C}$ for 48 hours prior to analysis.

\section{Microbiological Analysis}

\section{Isolation and Identification of LAB in Dadih}

$10 \mathrm{~g}$ of dadih prepared with various Lactobacillus species (L. acidophilus, L. plantarum and L. paracasei) and control (without starter culture) were homogenised with $90 \mathrm{ml}$ of $0.1 \%$ buffered peptone water (BPW) (Oxoid, UK) [1]. Then, the mixtures were diluted until dilution of $10^{-6} .0 .1 \mathrm{ml}$ from each dilution was spread on MRS agar (Merck, Germany) and MRS agar supplemented with $0.8 \%$ calcium carbonate $\left(\mathrm{CaCO}_{3}\right)$ by using spread plate method and incubated anaerobically in the $\mathrm{CO}_{2}$ incubator at $30^{\circ} \mathrm{C}$ for 48 hours. The morphology of the colonies were observed and recorded. The suspected colonies were further confirmed by using biochemical tests such as catalase test, oxidase test and Gram stain test. Then, it was further identified by using bioMerieux API $50 \mathrm{CHL}$ kit test system [6].

\section{Total Plate Count (TPC)}

$25 \mathrm{~g}$ of dadih was weighed and mix aseptically into a stomacher bag. Then, $225 \mathrm{ml}$ of $0.1 \%$ Buffered Peptone Water (Oxoid, UK) was added into the stomacher bag and the sample was blended in the stomacher [7]. Serial dilution was done until $10^{-5}$ dilution. Next, $0.1 \mathrm{ml}$ of the solution was pipetted out from each dilution into plates of plate count agar (PCA) and the spread plate was performed on the plates. Then, the plates were incubated aerobically in an incubator (Memmert, Germany) at $37^{\circ} \mathrm{C}$ for 48 hours. After incubation, the colonies on the plates were counted using the colony counter.

\section{LAB Count}

Lactic acid bacteria ( $L A B$ ) count was conducted to enumerate the LAB present in the dadih [8]. $25 \mathrm{~g}$ of dadih was homogenised with $225 \mathrm{ml}$ of $0.85 \%$ saline water in the stomacher. Then, homogenized dadih was appropriately diluted. $1.0 \mathrm{ml}$ of the solution was pipetted into a tube containing $9.0 \mathrm{ml}$ of saline and mixed gently in the tube. From the first dilution, $1.0 \mathrm{ml}$ was pipetted in to a second dilution tube containing saline. This step of serial dilution was repeated until $10^{-5}$ dilution. Then, $0.1 \mathrm{ml}$ of sample from each dilution was plated by spread plate method into duplicate plates of de Man, Rogosa and Sharpe (MRS) agar and MRS supplemented with $0.8 \% \mathrm{CaCO}_{3}$. The plates were incubated at $30^{\circ} \mathrm{C}$ for 48 hours in anaerobic condition. Then, the colonies on the plates which ranged from 30 to 300 were counted using the colony counter. The counted colonies were expressed in $\log _{10} \mathrm{CFU} / \mathrm{g}$. 


\section{Mould and Yeast Count}

Acidified Potato Dextrose Agar (PDA) with tartaric acid was used for the determination of mould and yeast count [1]. $10 \mathrm{ml}$ of sample was added into $90 \mathrm{ml}$ of $0.85 \%$ saline water and mixed well to make a serial dilution. $0.1 \mathrm{ml}$ of each dilution was spread plated on PDA. Then, the plates were incubated at 28 $\pm 2^{\circ} \mathrm{C}$ for 5 days. If there were no growth of mould and yeast, the plates were re-incubated for another 48 hours.

\section{Physicochemical Analysis of Dadih Determination of $\mathbf{p H}$}

The first reading of $\mathrm{pH}$ was taken after the dadih set and prior to being stored in the chiller at $4^{\circ} \mathrm{C}$. The $\mathrm{pH}$ meter was used in order to measure the $\mathrm{pH}$ of the sample. Prior to the $\mathrm{pH}$ determination, the sample was homogenised to obtain a uniform mixture for $\mathrm{pH}$ measurement [9]. Two readings for each replication were recorded and the mean value was calculated.

\section{Determination of Lactic Acid Content}

Total acidity of the dadih was expressed in terms of percentage of lactic acid produced by the bacteria. Titratable acidity (TA) was determined using the method of AOAC [10] by titrating with $0.1 \mathrm{~N} \mathrm{NaOH}$ solutions and a few drops of phenolphthalein were added to the sample as an indicator. Calculation of percentage of lactic is shown in Equation 1.

$$
\% \text { Lactic acid }=\frac{\text { Volume of titration }(\mathrm{ml}) \times \text { Normality } \mathrm{NaOH} \times 0.09 \times 100}{\text { Volume of sample }}
$$

\section{Determination of Total Soluble Solid (TSS)}

Total soluble solids or degree of Brix ('Brix) was determined by using a digital refractometer (Milwaukee MA871, Romania). This instrument measures the refractive index, which indicates how much a light beam is "bent" when it passes through the dadih. It measures the percentage of sugar and other soluble or dissolved solids in food. Refractometer was calibrated prior to use by dropping distilled water and the reading was adjusted to $0^{\circ}$ Brix. The accuracy was verified with dropping $5 \%$ sucrose solution ( $5 \mathrm{~g}$ sugar in $100 \mathrm{ml}$ distilled water). In this study, digital refractometer was used to determine the total soluble solids in the dadih. The samples were homogenized prior to analysis. Two readings were taken for each replication in order to obtain the mean or average of ${ }^{\circ}$ Brix.

\section{Determination of Colour}

Colorimeter (Minolta, Japan) was used to determine the colour of dadih based on $L^{*} a^{*} b^{*}$ colour system where $L^{*}$ represents the lightness of sample $\left(L^{*}=0\right.$ indicates black while $L^{*}=100$ indicates white), $a^{*}$ represents redness (positive) and greenness (negative) while $b^{*}$ represents yellowness (positive) and blueness (negative). The colorimeter was calibrated using white calibration plate before it was used to measure the colour intensity of the sample. The sample was homogenised and placed in a transparent container and the $L^{*} a * b^{*}$ values were measured.

\section{Determination of Texture}

In this study, the analysis was performed by using texture analyzer (Stable Micro system, Godalming, Surrey, UK) fitted with a $35 \mathrm{~mm}$ diameter probe (P36R) [9]. The compression strain used was $60 \%$ at speed of $5.0 \mathrm{~mm} / \mathrm{s}$ at $28^{\circ} \mathrm{C}$. The hardness of the sample was measured as the peak compression force (N) during the penetration of samples.

\section{Proximate Analysis}

The proximate analysis including the determination of moisture content, ash, crude fat, crude protein and carbohydrate was done according to AOAC method [10].

\section{Determination of Moisture}

The crucible and its lid were dried in a conventional oven at $100^{\circ} \mathrm{C}$. After 30 minutes, they were cooled in the desiccator. The weight of crucible was measured. $2 \mathrm{~g}$ of sample was put into the crucible and the 
sample was dried in the oven at $105^{\circ} \mathrm{C}$ for 24 hours until the weight become constant. Then, the crucible was cooled in the desiccator. Next, it was weighed without the lid. The calculation of the moisture of dadih was performed as shown in Equation 2 and 3 [10].

$$
\begin{aligned}
& \text { Dry matter }(\%)=\frac{\text { mass of dry sample }(g)}{\text { mass of initial sample }(g)} \times 100 \\
& \text { Wet matter }(\%)=100 \%-\text { dry matter }(\%)
\end{aligned}
$$

\section{Determination of Ash}

To ensure all impurities in the crucible were burned off, the crucible and the lid were placed in the conventional oven at $100^{\circ} \mathrm{C}$ for 30 minutes. The crucible without lid was weighed by using electronic balance after cooling in the desiccator. $5 \mathrm{~g}$ of sample was put into the crucible. The crucible and lid were placed in the muffle furnace. It was heated in the furnace at $550^{\circ} \mathrm{C}$ for 24 hours and the produced ash was weighed without the lid after cooling. Equation 4 was used to determine the ash content in dadih.

$$
\text { Ash }(\%)=\frac{\text { mass of ash }}{\text { mass of sample }} \times 100
$$

\section{Determination of Crude Fat}

Crude fat content was determined by using Soxtec Avanti 2050 System. Petroleum ether was used as extracting solvent in this system. The sample was pre-dried in the conventional oven at $130^{\circ} \mathrm{C}$ for 2 hours prior analysis. $2 \mathrm{~g}$ of sample was weighed on a filter paper and the sample was put into the extraction thimble. Then, the thimble with the sample was placed at the thimble stand by using a thimble handler. The aluminium extraction cup was weighed after drying and $70 \mathrm{ml}$ of petroleum ether was added into the cup in the fume chamber. The process of boiling, rinsing, recovery and pre-drying were done. Then, the cup was dried in the conventional oven at $103^{\circ} \mathrm{C}$ for 2 hours. The running water was turned off and the cup was cooled and weighed. The percentage of the crude fat was calculated by using Equation 5.

$$
\text { Percentage of crude fat }(\%)=\frac{\text { mass of extraction cup with fat-mass of extraction cup }}{\text { mass of sample }} \times 100
$$

\section{Data Analysis}

Minitab 14 software (Minitab Inc., USA) was used to conduct statistical analysis for all the results obtained from both physicochemical and microbiological analyses at confidence level of $\alpha=0.05$. The identification of LAB was analyzed by using APIweb ${ }^{T M}$ system. Parametric and non-parametric statistical methods were applied to determine the significant difference between the different types of dadih which have been inoculated with different commercial strains of LAB (L. plantarum, $L$. acidophilus and $L$. paracasei).

One-way analysis variance (ANOVA) was used for the parametric statistics in order to determine the significant difference between the dadih. Then, results with significant difference $(p<0.05)$ were analysed by using Fisher's Least Significant Difference (LSD) to determine the significant difference among independent variables. The data obtained were expressed in mean and standard deviation.

\section{Results and discussion}

\section{Isolation of LAB from Dadih}

The isolated bacteria from the samples have circular shape, milky colour and smooth surface. The result of biochemical characteristics of LAB is shown in Table 1. The purpose of this isolation was to determine the natural occurrence of LAB in control dadih which was prepared without addition of Lactobacillus cultures.

The microscopic examination revealed that the tested strains were Gram positive by showing purple colour in Gram staining. LAB strains are Gram-positive due to their cell wall structure which are thick, multi-layered peptidoglycan that are composed of proteins, teichoic acids and polysaccharides [11]. Thickened peptidoglycan layer in Gram-positive bacteria allows them to retain the stain. 
In this study, all the unknown isolated LAB exhibited negative catalase test which means no bubbles were formed after the addition of test reagent. It showed that the isolated LAB lacked in catalase. Therefore, the bacteria were unable to convert $\mathrm{H}_{2} \mathrm{O}_{2}$ into water and oxygen.

Table 1. Biochemical characteristics of lactic acid bacteria (LAB)

\begin{tabular}{|c|c|c|c|c|c|c|}
\hline \multirow[t]{2}{*}{ Sample } & \multirow[t]{2}{*}{ Coding } & \multirow[t]{2}{*}{ Shape } & \multicolumn{4}{|r|}{ Confirmation Tests } \\
\hline & & & $\begin{array}{c}\text { Oxidase } \\
\text { Test }\end{array}$ & $\begin{array}{c}\text { Catalase } \\
\text { Test }\end{array}$ & $\begin{array}{c}\text { Gram } \\
\text { Staining }\end{array}$ & Colony Morphology \\
\hline \multirow{4}{*}{$\begin{array}{l}\text { Cow's milk } \\
\text { dadih }\end{array}$} & Dc01Ad & Cocci & - & - & + & Pale yellow white, small, smooth, round colonies \\
\hline & Dc01Bc & Cocci & - & - & + & Pale yellow white, large, smooth, round colonies \\
\hline & $\mathrm{Dc01Ba}$ & Cocci & - & - & + & Yellow white, large, smooth, round colonies \\
\hline & $\mathrm{Dc01Ab}$ & Rod & - & - & + & Yellow white, small, smooth, round colonies \\
\hline \multirow{3}{*}{$\begin{array}{l}\text { Goat's } \\
\text { milk dadih }\end{array}$} & Dg01Ac & Cocci & - & - & + & Yellow white, large, smooth, round colonies \\
\hline & $\mathrm{Dg} 01 \mathrm{Ab}$ & Cocci & - & - & + & Pale yellow white, small, smooth, round colonies \\
\hline & Dg01Aa & Cocci & - & - & + & Yellow white, small, smooth, round colonies \\
\hline
\end{tabular}

The isolated bacteria lacked cytochrome c oxidase as the bacteria undergo fermentation metabolisms. Therefore, negative oxidase test was shown by all the isolated LAB where no colour changes were observed in the test. The results showed that all the bacteria cultures fit the classification of LAB as they are Gram-positive, catalase negative and oxidase negative.

\section{Identification of LAB}

Four cultures from cow's milk dadih and three cultures from goat's milk dadih were randomly selected for the phenotypic identification using API $50 \mathrm{CHL}$ kit. All isolates were Lactobacillus group with three different species; L. paracasei spp. paracasei, L. brevis and L. casei as summarised in Table 2. All cultures showed high degree of similarity $(95.1 \%$ to $99.9 \%)$.

Table 2. Identification of LAB isolates by phenotypic identification system using API $50 \mathrm{CHL}$ kit

\begin{tabular}{cclcl}
\hline Samples & Coding & \multicolumn{1}{c}{ Selected Organism } & Confidence Level & Description \\
\hline Cow's milk dadih & Dc01Ad & L. paracasei spp. paracasei & $97.4 \%$ & Very good identification \\
& Dc01Bc & L. previs & $95.1 \%$ & Good identification \\
& Dc01Ba & L. paracasei spp. paracasei & $98.3 \%$ & Very good identification \\
Goat's milk dadih & Dc01Ab & L. casei & $96.7 \%$ & Good identification \\
& Dg01Ac & L. paracasei spp. paracasei & $99.9 \%$ & Excellent identification \\
& Dg01Ab & L. paracasei spp. paracasei & $99.9 \%$ & Excellent identification \\
& Dg01Aa & L. paracasei spp. paracasei & $99.9 \%$ & Excellent identification \\
\hline
\end{tabular}

There is limited information about the isolated LAB from cow's and goat's milk dadih. Previously, the isolation was conducted on buffalo's milk dadih and the isolated LAB were L. plantarum, Lc. lactis subsp. lactis and L. brevis [1]. The findings of this study were in agreement with previous study where $L$. casei, L. fermentum and L. brevis were isolated from raw cow's milk [1].

\section{Microbiological Properties of Cultured Dadih}

\section{Total Plate Count (TPC)}

TPC was used to enumerate the amount of viable bacteria in food products as key indicator of the overall product is expected quality and safety once it reaches consumers [1]. Plate count agar was used for this analysis. Table 3 and Table 4 show TPC of dadih inoculated with different strains of lactic acid bacteria which are L. acidophilus, L. plantarum and L. paracasei. 
Table 3. General microbial load of cow's milk cultured dadih after 48 hours in cold storage $\left(4^{\circ} \mathrm{C}\right)$

\begin{tabular}{lc}
\hline Types of LAB added into dadih & TPC $\left(\log _{10}\right.$ CFU/g) \\
\hline Control dadih (without LAB) & $5.84 \pm 0.41^{\mathrm{a}}$ \\
L. acidophilus & $5.87 \pm 0.54^{\mathrm{a}}$ \\
L. plantarum & $6.00 \pm 0.45^{\mathrm{a}}$ \\
L. paracasei & $5.94 \pm 0.50^{\mathrm{a}}$ \\
\hline
\end{tabular}

Note: Data are expressed in mean \pm standard deviation. Means showing different superscript letter are significantly different $(p<0.05)$ between cow's milk dadih inoculated with LAB strains.

Table 4. General microbial load of goat milk cultured dadih after 48 hours in cold storage $\left(4^{\circ} \mathrm{C}\right)$

\begin{tabular}{lc}
\hline Types of LAB added into dadih & TPC $(\log$ CFU/g) \\
\hline Control dadih (without LAB) & $5.50 \pm 0.27^{\mathrm{a}}$ \\
L. acidophilus & $5.75 \pm 0.32^{\mathrm{a}}$ \\
L. plantarum & $5.82 \pm 0.85^{\mathrm{a}}$ \\
L. paracasei & $5.96 \pm 0.43^{\mathrm{a}}$ \\
\hline
\end{tabular}

Note: Data are expressed in mean \pm standard deviation. Means showing different superscript letter are significantly different $(p<0.05)$ between goat milk dadih inoculated with LAB strains.

Based on Table 3 and Table 4, there were no significant differences ( $p>0.05$ ) of general microbial load among the samples for both types of dadih. The obtained results were similar to the number of bacteria in LAB count. This result demonstrated that almost all microorganisms in TPC were LAB. In addition, it reflected that the cooking process used adequate amount of heat with good combination of time and temperature that was capable to kill most spoilage bacteria and pathogenic microorganisms which can reduce the shelf life of the dadih.

Besides, LAB can inhibit the growth of spoilage organisms and pathogenic bacteria by producing metabolites for instance: organic acids, hydrogen peroxide, bacteriocins-like substances and diacetyl [1]. Therefore, inoculation of those commercial strains of LAB can inhibit the growth of undesired microorganisms.

\section{Viability of LAB}

Viability of $L A B$ is the ability of $L A B$ to survive under given conditions. It also can be related to the colony's ability to replicate. In this study, enumeration of LAB was done by spreading $0.1 \mathrm{ml}$ diluents or diluted sample on the de Mann, Rogosa and Sharpe (MRS) agar and MRS agar supplemented with $\mathrm{CaCO}_{3}$.

Table 5. Viability of LAB of cow's milk dadih after 48 hours in cold storage $\left(4^{\circ} \mathrm{C}\right)$

\begin{tabular}{lcc}
\hline \multicolumn{1}{c}{ Types of LAB added into dadih } & \multicolumn{2}{c}{${\text { LAB Count }\left(\log _{10} \text { CFU/g) }\right.}^{\text {MRS agar supplemented with CaCO }_{3}}$} \\
\cline { 2 - 3 } Control dadih & MRS agar & $4.96 \pm 0.93^{\mathrm{a}}$ \\
L. acidophilus & $6.06 \pm 0.91^{\mathrm{a}}$ & $5.51 \pm 0.27^{\mathrm{a}}$ \\
L. plantarum & $5.90 \pm 0.38^{\mathrm{a}}$ & $5.52 \pm 0.07^{\mathrm{a}}$ \\
L. paracasei & $5.91 \pm 0.29^{\mathrm{a}}$ & $5.40 \pm 0.17^{\mathrm{a}}$ \\
\hline
\end{tabular}

Note: Data are expressed in mean \pm standard deviation. Means within the same column showing different superscript letter are not significantly different $(p>0.05)$ between cow's milk dadih inoculated with LAB strains.

Table 6. Viability of LAB of goat milk dadih after 48 hours in cold storage $\left(4^{\circ} \mathrm{C}\right)$

\begin{tabular}{llc}
\hline \multicolumn{1}{c}{ Types of LAB added into dadih } & \multicolumn{2}{c}{${\text { LAB Count }\left(\log _{10} \text { CFU/g) }\right.}^{\text {MRS agar supplemented with CaCO }_{3}}$} \\
\cline { 2 - 3 } & MRS agar & $2.00 \pm 2.83^{\mathrm{a}}$ \\
\hline Control dadih & $5.19 \pm 0.16^{\mathrm{a}}$ & $5.14 \pm 0.50^{\mathrm{a}}$ \\
L. acidophilus & $5.75 \pm 0.02^{\mathrm{a}}$ & $5.11 \pm 0.72^{\mathrm{a}}$ \\
L. plantarum & $5.88 \pm 0.57^{\mathrm{a}}$ & $5.00 \pm 0.20^{\mathrm{a}}$ \\
L. paracasei & $5.77 \pm 0.10^{\mathrm{a}}$ & \\
\hline
\end{tabular}

Note: Data are expressed in mean \pm standard deviation. Means within the same column showing different superscript letter are not significantly different $(p>0.05)$ between goat milk dadih inoculated with LAB strains. 
There was no significant difference $(P>0.05)$ among the samples for both types of dadih in terms of the viability of LAB (Table 5 and Table 6 ). The initial amount of $L$. acidophilus, L. plantarum and L. paracasei that had been incorporated into cow milk dadih samples were 6.94, 7.07 and $6.94 \log _{10}$ CFU/g accordingly. It was observed that there was a slight decreased in the LAB count after they had been incorporated into the cow's milk dadih samples which were $5.90 \log _{10}$ CFU/g for L. acidophilus, $5.91 \log _{10}$ $\mathrm{CFU} / \mathrm{g}$ for L. plantarum and $5.73 \log _{10} \mathrm{CFU} / \mathrm{g}$ for L. paracasei.

Besides, the initial count of $L$. acidophilus, $L$. plantarum and $L$. paracasei that had been incorporated into goat milk dadih samples were 6.91, 7.44 and $6.93 \log _{10} \mathrm{CFU} / \mathrm{g}$ accordingly. The amount of the LAB observed on MRS agar also decreased as compared to the initial count after they had been incorporated into the goat milk dadih samples which were $5.75 \log _{10} \mathrm{CFU} / \mathrm{g}$ for $L$. acidophilus, $5.88 \log _{10} \mathrm{CFU} / \mathrm{g}$ for $L$. plantarum and $5.77 \log _{10} \mathrm{CFU} / \mathrm{g}$ for L. paracasei.

The optimal temperature for LAB growth is between 37 to $41^{\circ} \mathrm{C}$ [20]. But, these bacteria can still grow at refrigerated temperature. It was proven by the noticeable reduction of $\mathrm{pH}$ during storage at $4^{\circ} \mathrm{C}$. The $\mathrm{LAB}$ can grow in the dadih due to the sufficient nutrients provided by the dadih for instance, the carbon source from lactose and the nitrogen source from the milk protein.

The reduced number of $L A B$ from the initial count might be due to the cell adaptation. Bacteria require certain period of time to adapt to new environment. In addition, the initial number of LAB was different due to the environmental conditions.

Besides, the bacteria grew slowly in milk products because of lack of proteolytic activity and this might be a factor in the reduction of cell counts in the samples [2]. LAB are considered weakly proteolytic compared to other groups of bacteria such as Pseudomonas and Proteus [1]. However, most LAB strains rely on complex proteolytic system to liberate essential amino acids from food that are rich in protein during the preparation of inoculum.

\section{Mould and Yeast Count}

Mould and yeast can affect the quality and safety of food products. They might spoil the food by producing off-flavour, discolouration and disintegration of the food structure. Table 7 and Table 8 present the mould and yeast count (MYC) for cow milk dadih and goat milk dadih accordingly. Acidified potato dextrose agar (PDA) was used in order to determine the growth of mould and yeast where both types of microorganisms are good indicators of food spoilage.

Table 7. Mould and yeast count of cow's milk dadih after 48 hours in cold storage $\left(4^{\circ} \mathrm{C}\right)$

\begin{tabular}{ll}
\hline \multicolumn{1}{c}{ Types of LAB added into dadih } & MYC $\left(\log _{10}\right.$ CFU/g) \\
\hline Control dadih & Less than $1 \log _{10}$ CFU/g \\
L. acidophilus & Less than $1 \log _{10}$ CFU/g \\
L. plantarum & Less than $1 \log _{10}$ CFU/g \\
L. paracasei & Less than $1 \log _{10}$ CFU/g \\
\hline
\end{tabular}

Table 8. Mould and yeast count of goat milk dadih after 48 hours in cold storage $\left(4^{\circ} \mathrm{C}\right)$

\begin{tabular}{ll}
\hline \multicolumn{1}{c}{ Types of LAB added into dadih } & MYC $\left(\log _{10}\right.$ CFU/g) \\
\hline Control dadih & Less than $1 \log _{10}$ CFU/g \\
L. acidophilus & Less than $1 \log _{10}$ CFU/g \\
L. plantarum & Less than $1 \log _{10}$ CFU/g \\
L. paracasei & Less than $1 \log _{10}$ CFU/g \\
\hline
\end{tabular}

Based on the Table 7 and Table 8, there were less than $1 \log _{10}$ CFU/g of mould and yeast count observed on the PDA agar. According to the Malaysian Food Act (1983) and the Food Regulations (1985), milk and dairy products are regarded as safe if the total aerobic count does not exceed $1 \times 10^{5} \mathrm{CFU} / \mathrm{ml}$. 
Dadih is one the of dairy-based products that contain lots of nutrients. It is a good growth medium for many microorganisms. Various types of microorganisms are found in milk. The main ingredients of dadih include Gram-positive, Gram-negative bacteria, mould and yeast. Yeasts are usually found in low $\mathrm{pH}$ dairy products but different yeast species were also found in neutral-pH raw and market milk [12]. It happens due to contamination during milking process or recontamination after heat treatment.

In this study, the mould and yeast were not detected because they were destroyed during cooking process where high heat $\left(85^{\circ} \mathrm{C}\right)$ was applied. Besides, both types of microorganisms were undetected due to the presence of dominant $L A B$ in the dadih. The competitions of nutrients occur as the microorganisms require nutrients such as amino acids, lactose, fatty acids and certain minerals for their growth.

The production of metabolites such as lactic acid by the LAB can inhibit the mould and yeast activity. This is supported by previous study where antifungal compound produced by $L$. plantarum showed activity against Aspergillus spp. in the food products [13]. The acid produced by LAB has a specific effect on the metabolic activity of the cytoplasm of the fungus and directly inhibit fungal growth.

\section{Physicochemical Properties of Cultured Dadih}

\section{pH Analysis of Cultured Dadih}

$\mathrm{pH}$ is a measurement of free hydrogen ion $\left(\mathrm{H}^{+}\right)$in a solution. In this study, the $\mathrm{pH}$ value was measured by using a $\mathrm{pH}$ meter. Figure 1 and 2 show the mean $\mathrm{pH}$ of the cultured cow's milk dadih and goat's milk dadih respectively.

Both Figure 1 and Figure 2 show that there were significant differences $(p<0.05)$ in the $\mathrm{pH}$ values of the dadih samples. $\mathrm{pH}$ values for samples inoculated with $\mathrm{LAB}$ decreased after 48 hours stored at $4^{\circ} \mathrm{C}$. The $\mathrm{pH}$ value of cultured cow's milk dadih dropped from 6.68 to approximately 6.40 while cultured goat milk dadih dropped from 6.70 to approximately 6.50. Figure 1 illustrates that cow's milk dadih inoculated with $L$. plantarum had the lowest $\mathrm{pH}(6.36 \pm 0.03)$ followed by the sample inoculated with $L$. acidophilus and L. paracasei (6.40 \pm 0.09 and $6.48 \pm 0.04$ respectively). As shown in Figure 2, L. acidophilus had the lowest $\mathrm{pH}$ followed by $L$. paracasei and $L$. plantarum $(6.38 \pm 0.04,6.43 \pm 0.02$ and $6.47 \pm 0.07$ respectively).

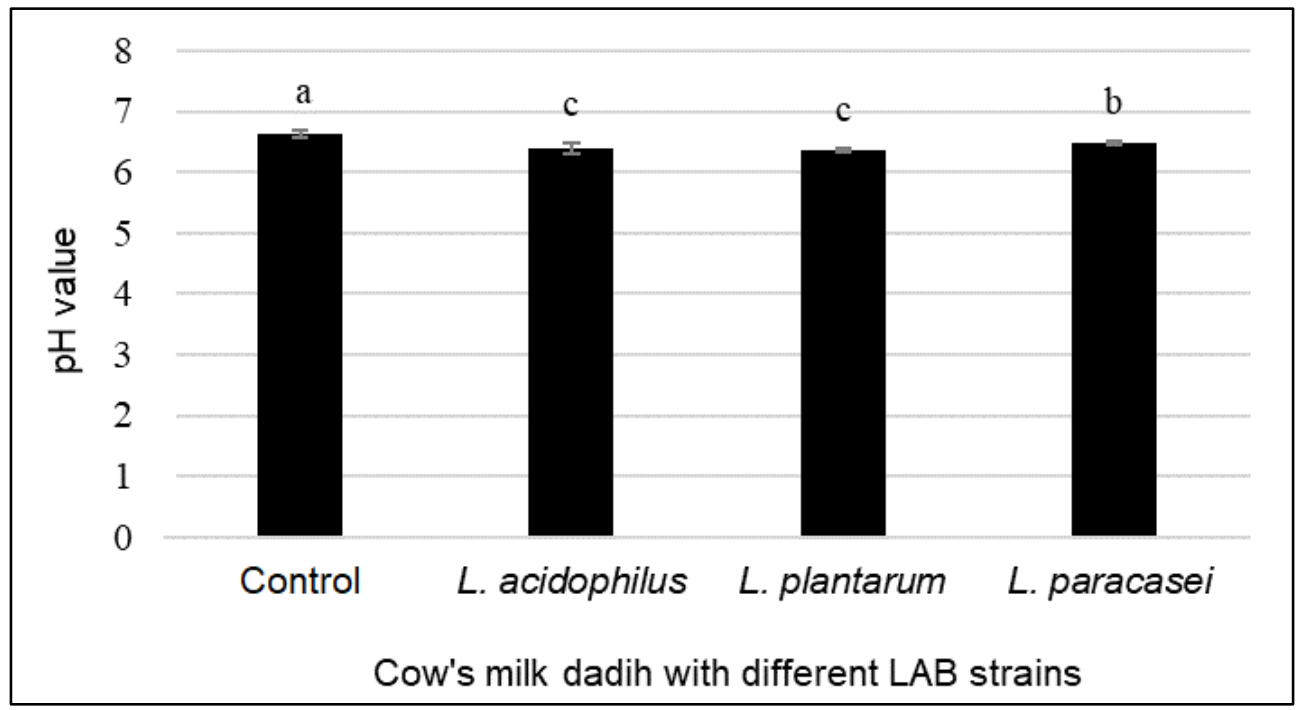

Figure 1. Mean $\mathrm{pH}$ of cow's milk dadih with different strains of lactic acid bacteria Note: Mean value with different letters are significantly different $(p<0.05)$. 


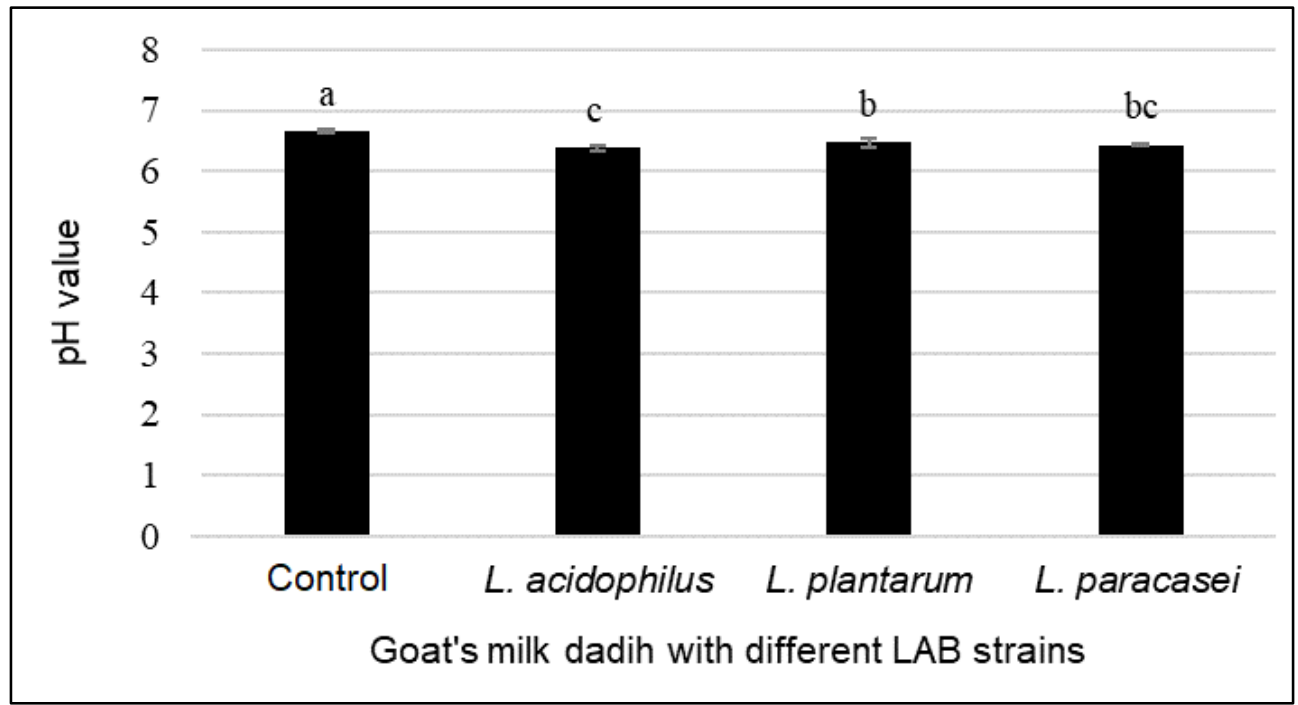

Figure 2. Mean pH of goat's milk dadih with different strains of lactic acid bacteria Note: Mean value with different letters are significantly different $(p<0.05)$.

Decrease in $\mathrm{pH}$ value was due to the production of lactic acid by the lactic acid bacteria (LAB) in the samples. LAB present in samples utilized carbon sources especially from lactose to form organic acids such as lactic acid, acetaldehyde and diacetyl. Organic acid produced by the LAB can be measured using $\mathrm{pH}$ meter and titratable acidity method. The concentration of hydrogen ion was measured in order to determine the $\mathrm{pH}$ and total acidity of the samples. The differences in concentration of hydrogen ion can be used as an indicator for different growth rate of bacteria [14].

The data of $\mathrm{pH}$ in this study was supported by previous study where the $\mathrm{pH}$ of control probiotic dadih was lower than control sample without probiotic [2]. The decline of $\mathrm{pH}$ value may be due to the interaction of the different $L A B$ strains in the samples since there were few species of $L A B$ found in the dadih before it had been supplemented with commercial strains of LAB.

Previous study on fermented Indonesian dadih showed that the $\mathrm{pH}$ of dadih made from buffalo's milk have low $\mathrm{pH}$ ranging from $\mathrm{pH} 4.0$ to 4.2 [1]. The significant difference between the $\mathrm{pH}$ of Indonesian and Malaysian style dadih are due to the different preparation methods. Indonesian dadih is prepared by fermenting raw buffalo's milk in bamboo while, Malaysian dadih is prepared by cooking the milk prior to fermentation.

\section{Titratable Acidity of Cultured Dadih}

LAB utilized lactose as their energy substrate and produce metabolite which is lactic acid [2]. The mean of total acidity was expressed as percentage of lactic acid as illustrated in Figure 3 and Figure 4.

Figure 3 shows that there was no significant difference $(p>0.05)$ in percentage of lactic acid of cow's milk dadih inoculated with different strains of LAB. However, there was significant difference $(p<0.05)$ in lactic acid content of cultured goat's milk dadih. Based on Figure 4, there was significant difference between the amount of lactic acid produced by $L$. acidophilus $(0.39 \pm 0.03 \%)$ and $L$. paracasei $(0.50 \pm 0.06 \%)$.

The percentage of titratable acidity is closely related to the $\mathrm{pH}$ of the samples. Based on the findings from this study, the samples that were inoculated with LAB have high percentage of titratable acidity compared to the control sample. Previous study showed that sample with high amount of lactic acid has low $\mathrm{pH}$ value [2]. This trend in increasing titratable acidity and decreasing $\mathrm{pH}$ were also reported which could be attributed to the accumulation of organic acid resulting from the activities of $L A B$ during fermentation [15]. Different amount of produced acid was measured due to the differential microbial population in the samples. 


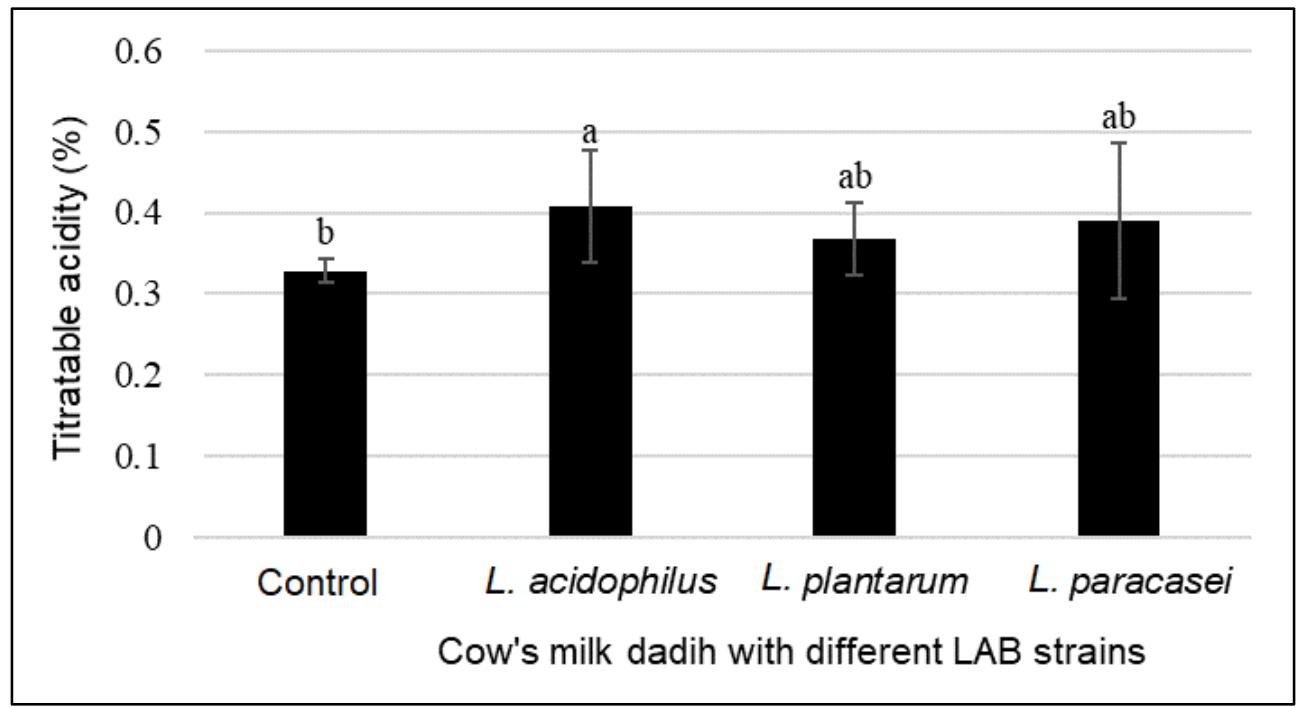

Figure 3. Mean of titratable acidity (\%) of cow's milk dadih with different strains of lactic acid bacteria Note: Mean value with different letters are significantly different $(p<0.05)$.

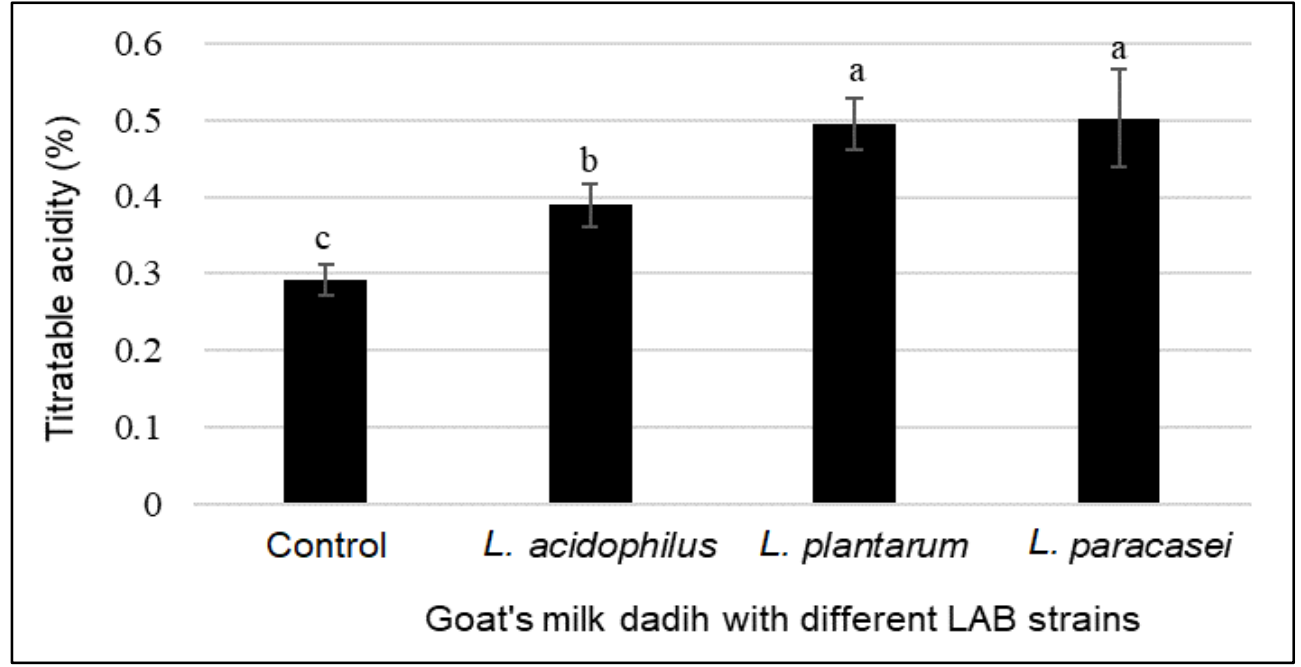

Figure 4. Mean of titratable acidity (\%) of goat's milk dadih with different strains of lactic acid bacteria Note: Mean value with different letters are significantly different $(p<0.05)$.

No standard has been established for total titratable acidity (TTA) of dadih. However, the standard TTA for yogurt is not less than $0.5 \%$ calculated as lactic acid (Food regulations, 1985). According to Codex standard, fermented milk should have TTA of at least $0.3 \%$ [16]. Therefore, cow's milk dadih and goat's milk dadih in this study have achieved the standard given by Codex.

Previous study showed that the percentage of TTA of dadih from buffalo's milk ranges from 1.2 to $1.3 \%$ [1]. Different types of milk used contribute to the variation in total titratable acidity of the dadih. Different types of microorganisms present in dadih influence the TTA of the food products. It is because the acid production is dependent on the strains of LAB.

\section{Total Soluble Solids (TSS) of Cultured Dadih}

TSS of dadih is expressed in Brix. Besides sugar, organic amino acids and soluble pectin also included in soluble solid contents. However, most of the total soluble solids in food are sugar. Therefore, TSS is 
always expressed as sugar content. In this study, TSS of the dadih was measured using the digital refractometer. Figures 5 and Figure 6 show the mean of total soluble solids of cultured cow's milk dadih and goat milk dadih, respectively.

As seen in Figure 5 and Figure 6, there were significant differences $(p<0.05)$ in terms of total soluble solids of both types of samples which are cultured cow's milk dadih and goat's milk dadih. There was difference between cow's milk dadih inoculated with $L$. paracasei and $L$. plantarum. The difference can also be seen between the goat's milk dadih inoculated with $L$. acidophilus and $L$. plantarum.

Samples that have been inoculated with $L$. acidophilus have the least amount of total soluble solid while control sample or samples without commercial strains of LAB have the highest amount of total soluble solids. This result indicates that the LAB utilised the sugar during fermentation process. Meanwhile, the higher value of TSS in control dadih is probably due to the higher amount of lactose presence.

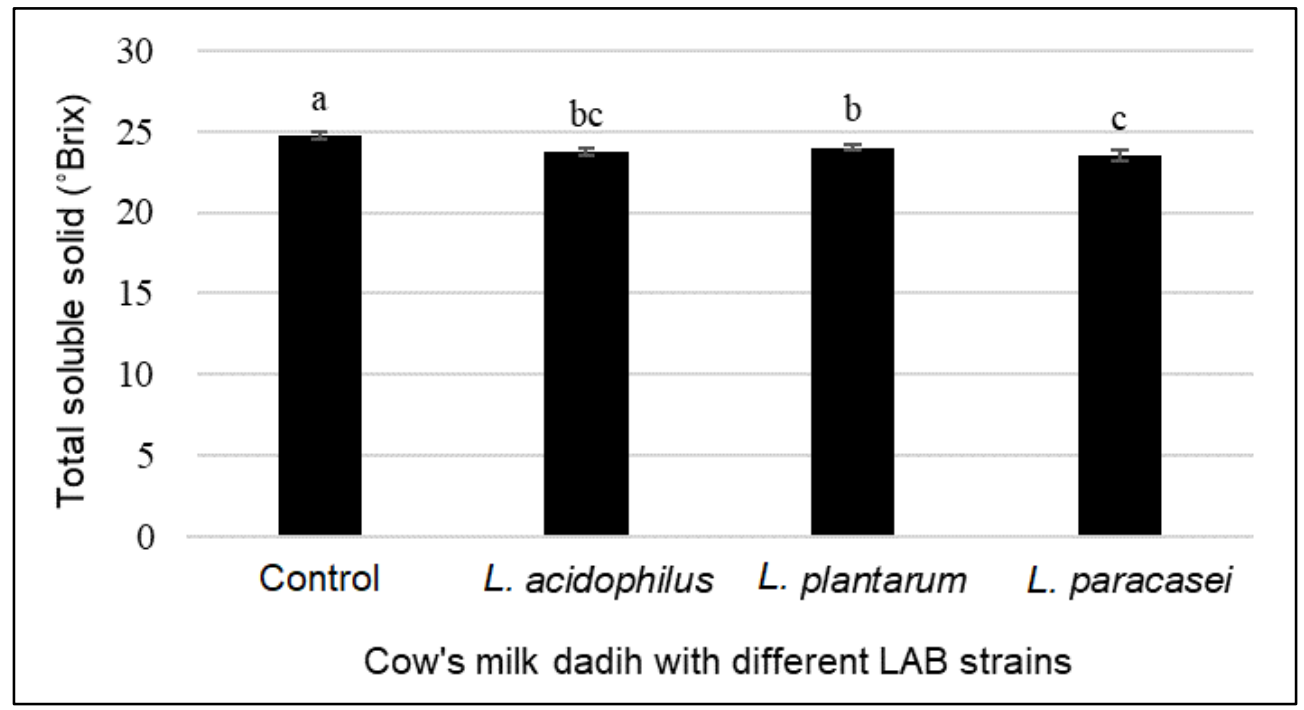

Figure 5. Mean value of total soluble solid of cow's milk dadih with different strains of lactic acid bacteria Note: Mean value with different letters are significantly different $(p<0.05)$.

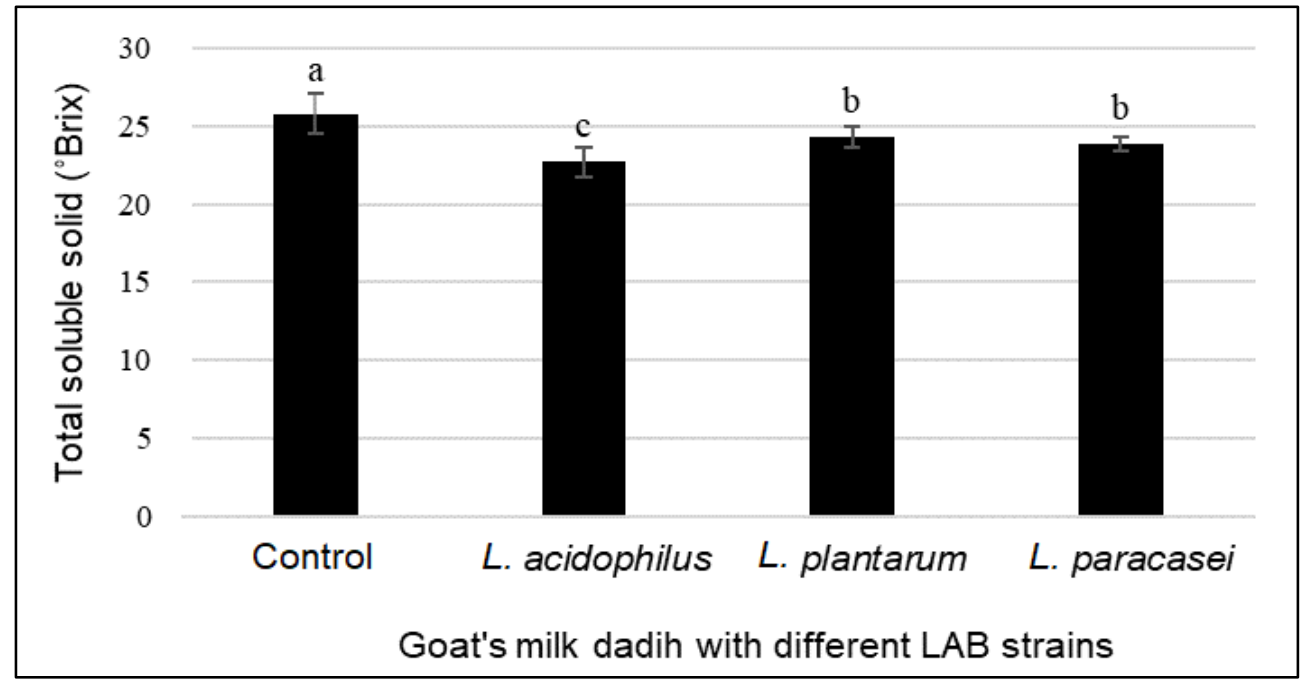

Figure 6. Mean value of total soluble solid of goat's milk dadih with different strains of lactic acid bacteria Note: Mean value with different letters are significantly different $(p<0.05)$. 


\section{Colour of Cultured Dadih}

In this study, CIE L*a*b* Colour System was used to determine the colour of cow's milk dadih and goat's milk dadih with different strains of LAB. $L^{*}$ represents the lightness, a* represent redness while $b^{*}$ represents yellowness. Figure 7 shows the $L^{*}, a^{*}$ and $b^{*}$ value for the cow's milk dadih and Figure 8 shows goat's milk dadih inoculated with different strains of LAB such as $L$. acidophilus, $L$. plantarum and L. paracasei.

Based on this study, there was no significant effect $(p>0.05)$ exhibited by the cow's milk dadih with different strains of $L A B$ on the $L^{*}, a^{*}$ and $b^{*}$ values. But, there was significant effect $(p<0.05)$ on the $L^{*}$, $a^{*}$ and $b^{*}$ values between the goat milk dadih inoculated with different strains of LAB. As shown in Figure 7 and Figure 8, parameter $L^{*}$ which indicates the degree of lightness had positive values where it showed that the colour of the dadih was light. Parameter $a^{*}$ (redness) had negative values, appearing slightly green in colour, while parameter $b^{*}$ (yellowness) had positive values, appearing slightly yellow in colour.

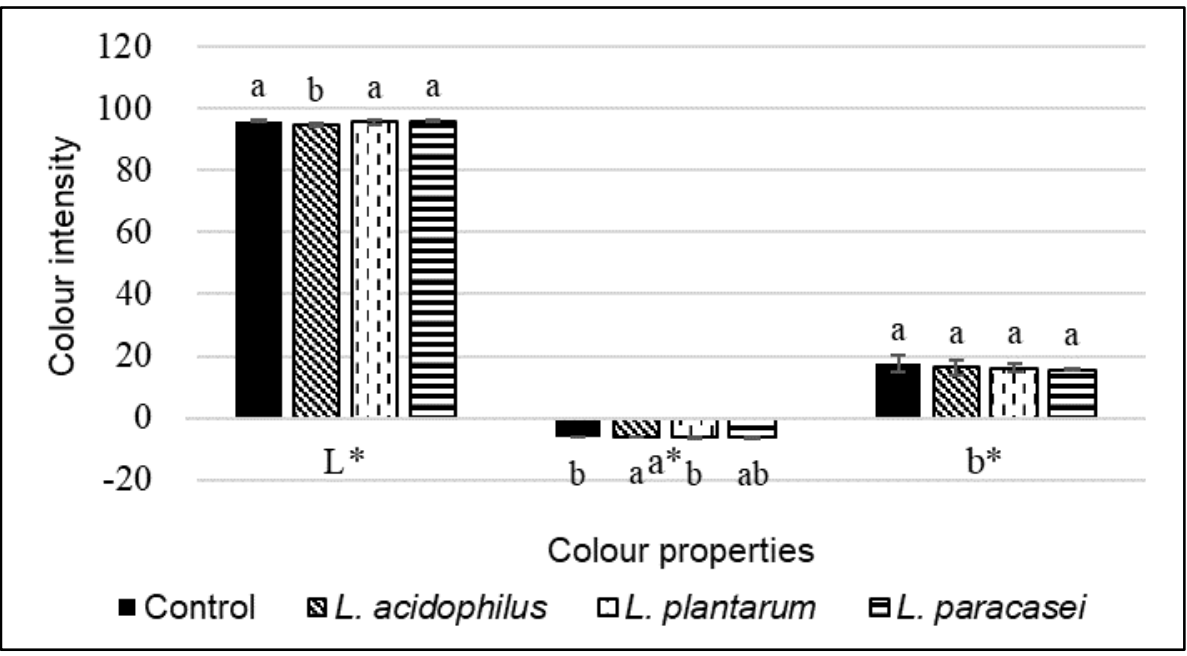

Figure 7. Colour of cow's milk dadih with different strains of LAB Note: Mean value with different letters are significantly different $(p<0.05)$.

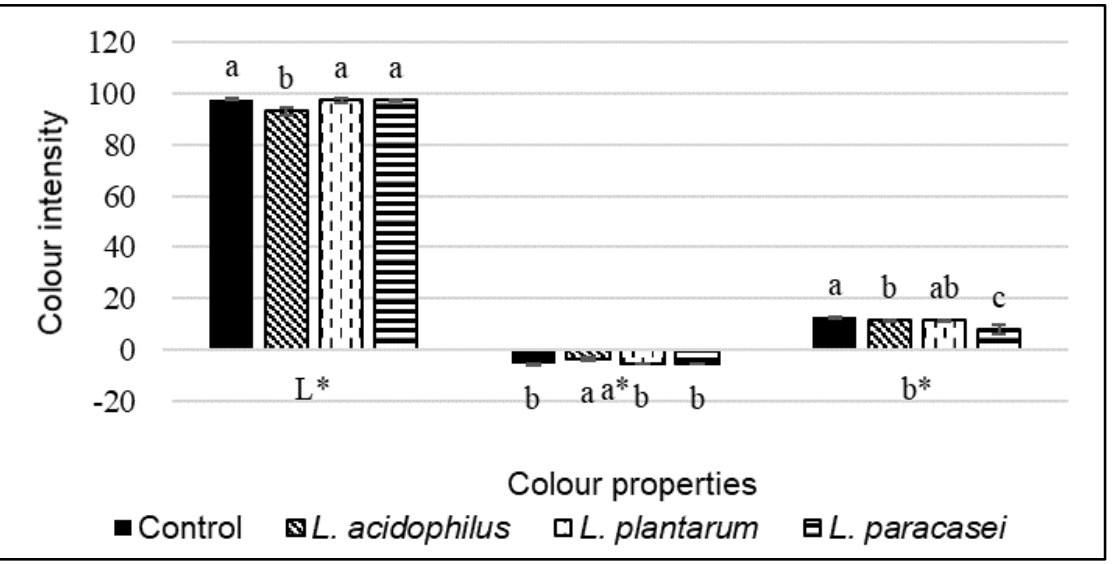

Figure 8. Colour of goat's milk dadih with different strains of LAB Note: Mean value with different letters are significantly different $(p<0.05)$.

Value of $L^{*}$ was higher because the colour of the dadih is ranges from white to light yellow. The white colour of dadih was due to the scattered light by the fat globules, casein micelles and calcium phosphate. The dadih had negative $a^{*}$ value which reflects greenness in colour while the positive $b^{*}$ value was due 
to the presence of xanthophyll and $\beta$-carotene pigments [17].

$\beta$-carotene is the pigment which is responsible for contributing the yellow colour of milk. Indirectly, it gives the colour to the dadih. It is established that $\beta$-carotene is present greater in cow's milk but less in goat's milk [1]. The presence of $\beta$-carotene pigment in cow's milk cause an increase in the intensity of yellow colour in any formulations produced with this type of milk [18]. $\beta$-carotene is fairly resistant to heat, $\mathrm{pH}$ changes and water leaching since it is fat soluble [19].

\section{Hardness of Cultured Dadih}

Hardness is one of the parameters used to describe a product which shows substantial resistance to deformation. The texture analyser with P36R probe was used in order to determine the hardness of cow's milk dadih and goat's milk dadih inoculated with different strains of LAB. The hardness value is the peak force that occurs during the first compression. The mean of hardness value of cow's milk dadih and goat's milk dadih inoculated with different strains of LAB is shown in Figure 9 and Figure 10, accordingly.

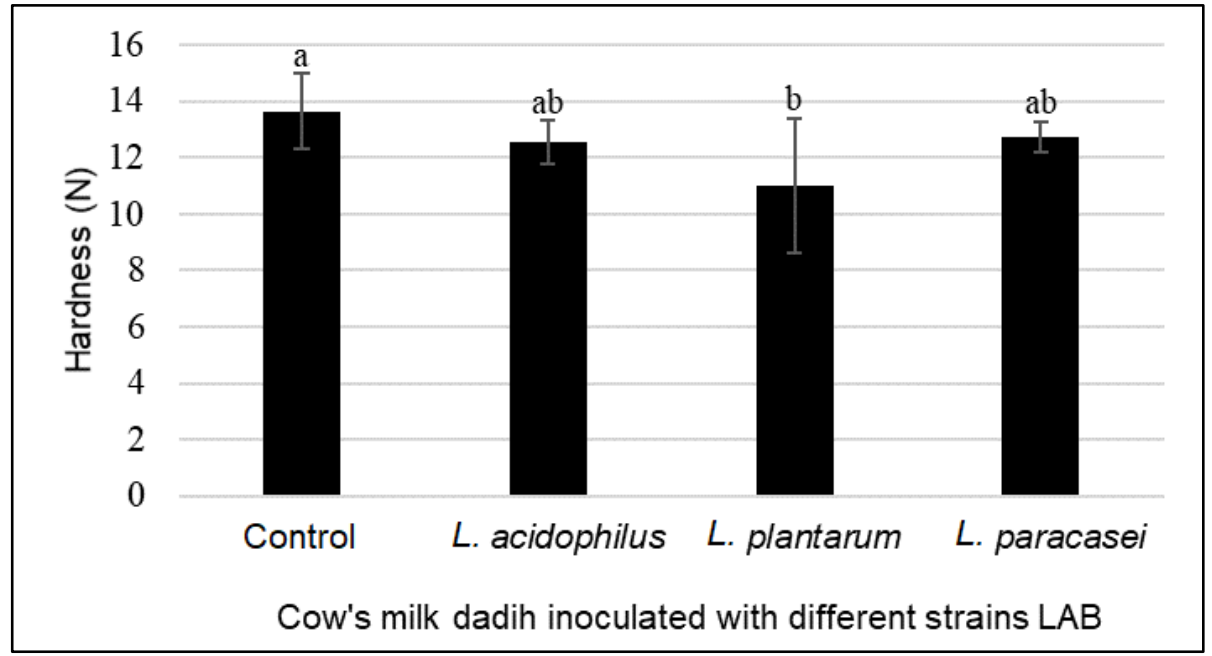

Figure 9. Mean of hardness of cow's milk dadih with different strains of lactic acid bacteria Note: Mean value with different letters are significantly different $(p<0.05)$.

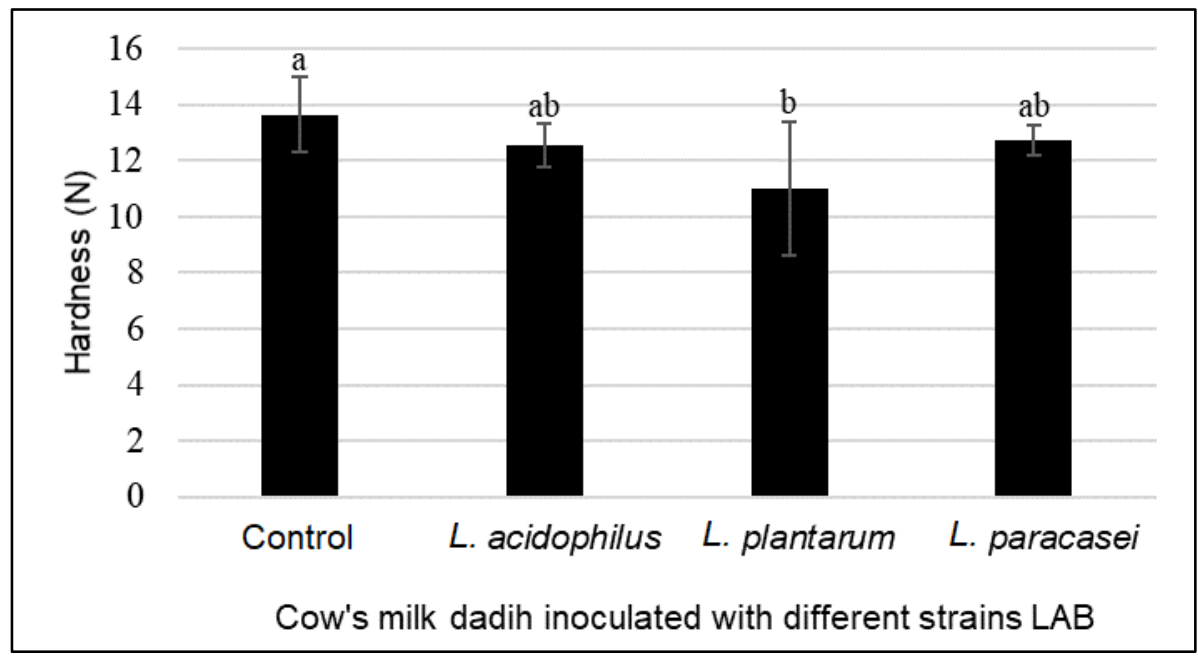

Figure 10. Mean of hardness of goat's milk dadih with different strains of lactic acid bacteria Note: Mean value with different letters are significantly different $(p<0.05)$. 
Significant differences $(p<0.05)$ were found in hardness for both types of dadih which are cow's milk dadih and goat's milk dadih which had been inoculated with different strains of lactic acid bacteria (LAB). As shown in Figure 9 and Figure 10, the values for hardness were highest for the dadih which were not inoculated with $L A B$. The differences of hardness between the samples that have been inoculated with $L A B$ are due to the different initial microbial load for each inoculum and the ability of the LAB to breakdown the protein or also known as proteolysis.

The dadih with LAB were found to be softer than the dadih without LAB this occurs because the bacteria can break down the proteins with the aid of protease that have been produced by them. Acid produced by $L A B$ is capable to dissolve calcium that acts as glue that cross-links the protein and gives structure to the dadih [20]. When the calcium is being dissolved, the protein network is loosening and the dadih becomes softer. Besides that, fat content also affected the hardness of the dadih. The reduction of fat influenced the protein network and they caused the dadih to have higher resistance to deformation [1].

There is no standard for hardness of dadih. Previous studies showed that tropical-fruit dadih have hardness ranging from 0.57 to $0.69 \mathrm{~N}$ [9] while the hardness of dadih made from skim milk was $17.55 \mathrm{~N}$ [21]. The variation of hardness of dadih was caused by the type of raw material and processing method.

\section{Proximate Analysis of Cultured Dadih}

\section{Moisture Content of Cultured Dadih}

Figure 11 and Figure 12 illustrate the mean of moisture content of inoculated cow's milk dadih and goat's milk dadih, respectively.

No significant differences ( $p>0.05$ ) in moisture content were observed among the cow's milk dadih as shown in Figure 11 while there were significant differences in the moisture content of goat's milk dadih as seen in Figure 12. The moisture content observed from cow's milk dadih ranged from 66.68 to $68.66 \%$ while goat's milk dadih ranged from 68.67 to $70.89 \%$. The chemical composition of the samples, including the moisture content, was inconsistent. The inconsistency of dairy product's composition is influenced by the nutritional status of the animal is lactation stage and genetic factors [2, 22]. The amount of moisture is lower compared to the actual moisture content in milk. This is due to the evaporation process that occurs during the cooking process. Besides, the bonding between water and milk protein occurred to a certain extent causing the decreased amount of moisture content in the samples [9].

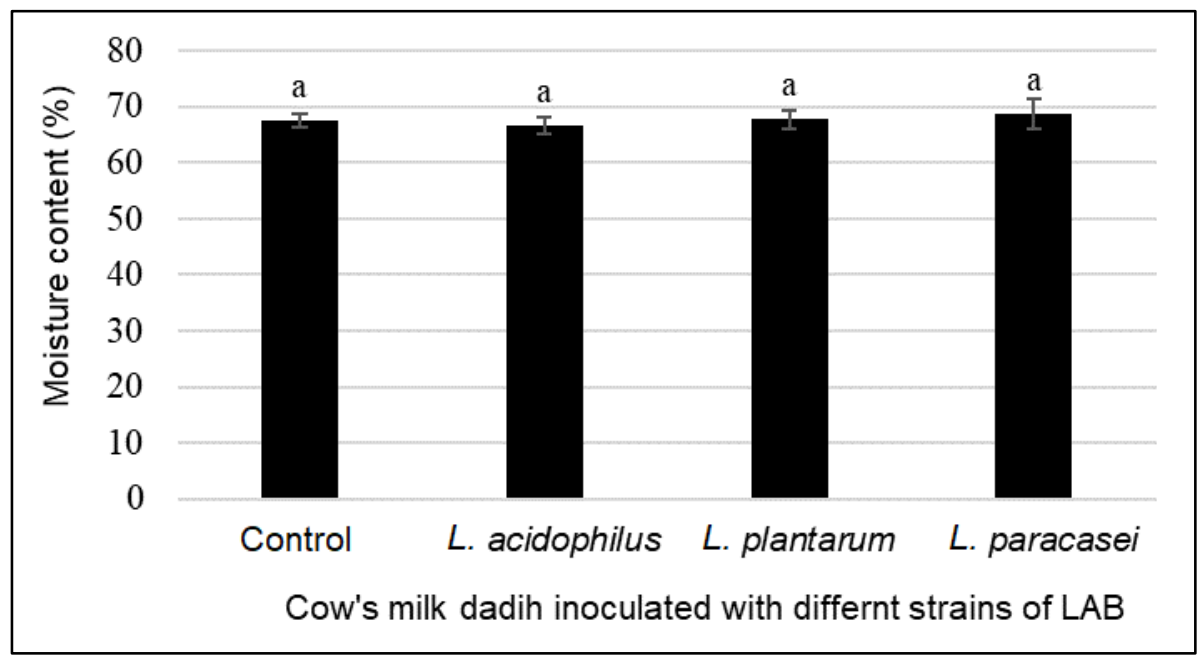

Figure 11. Mean value of moisture content of cow's milk dadih with different strains of lactic acid bacteria

Note: Mean value with different letters are significantly different $(p<0.05)$. 


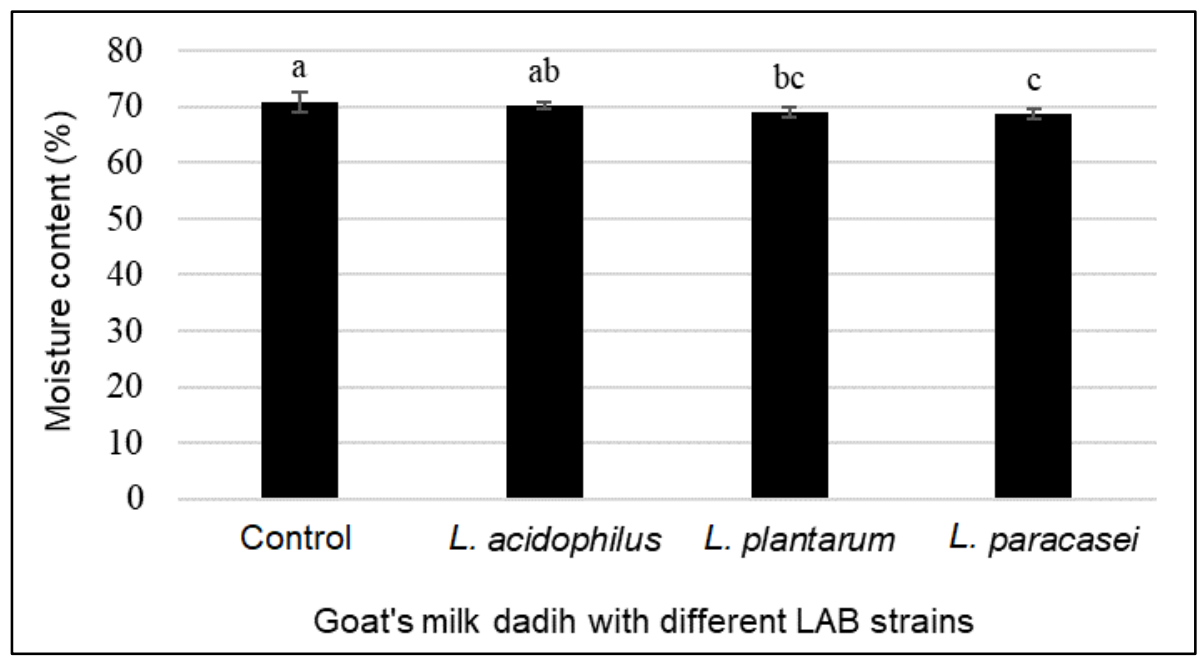

Figure 12. Mean value of moisture content of goat's milk dadih with different strains of lactic acid bacteria Note: Mean value with different letters are significantly different $(p<0.05)$.

The moisture content of goat's milk dadih inoculated with L. paracasei was lower than control goat's milk dadih. The difference observed in moisture content could be due to increment in dry matter content as a result of microbial cell proliferation during fermentation process. Decreasing in moisture was also reported by previous researchers in yogurt fermentation [1]. As fermentation time increased, moisture content decreased while the total solid content in fermenting yogurt increased. In conclusion, the decrease in moisture generally increase the concentration of nutrients.

\section{Ash content of Cultured Dadih}

Ash refers to the inorganic residue remaining after complete oxidation of organic matter in a food sample. It is important to determine the ash content because it is an important quality attribute for some food ingredients [21]. Figure 13 and Figure 14 show the mean of ash content in cultured cow's milk dadih and goat's milk dadih, respectively.

Ash content is the amount of non-combustible matter and total minerals present in food [9]. As shown in Figure 13 and Figure 14, both cow's milk dadih and goat's milk dadih were significantly different in terms of ash content. For the cow's milk dadih, the highest amount of ash can be found in the control sample with $1.69 \% \pm 0.05$ ash content while the least amount of ash was determined to be from the sample inoculated with $L$. paracasei with about $1.49 \% \pm 0.01$ ash content. As illustrated in Figure 14 , control goat's milk dadih had the highest amount of ash content which was $1.36 \% \pm 0.04$ followed by goat's milk dadih inoculated with $L$. acidophilus, $L$. plantarum and $L$. paracasei with ash content at $1.32 \% \pm 0.02$, $1.28 \% \pm 0.02$ and $1.11 \% \pm 0.10$, respectively.

The dadih inoculated with bacteria had less amount of ash content than the control dadih. It might be due to the presence of the lactic acid bacteria in the samples. Minerals such as magnesium, sodium and phosphorus have promoting effect for the growth of LAB [2]. Previous study conducted in production of wine reported that the minerals have been shown to be key enzymes co factor in many metabolisms of microorganisms and they are very important for LAB growth [23].

\section{Crude fat of Cultured Dadih}

Crude fat analysis was done by the Soxhlet method as suggested in AOAC 2000. Figure 15 and Figure 16 show the crude fat content in the cow's milk dadih and goat's milk dadih inoculated with different strains of $L A B$. 


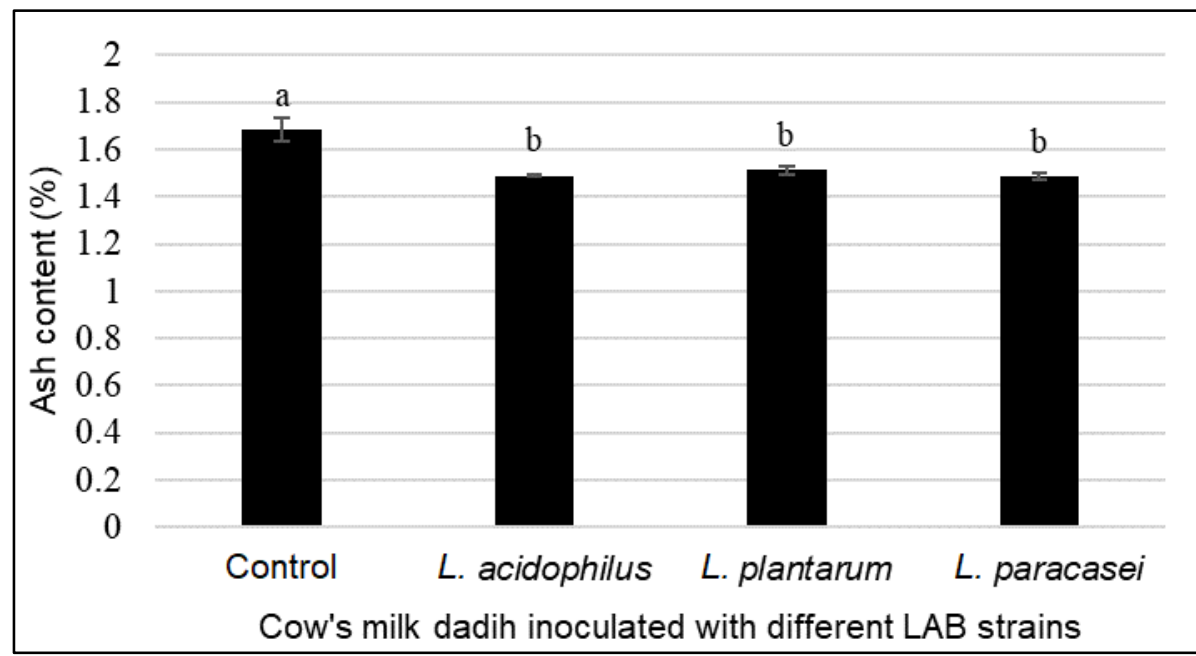

Figure 13. Mean value of ash content of cow's milk dadih with different strains of lactic acid bacteria Note: Mean value with different letters are significantly different $(p<0.05)$.

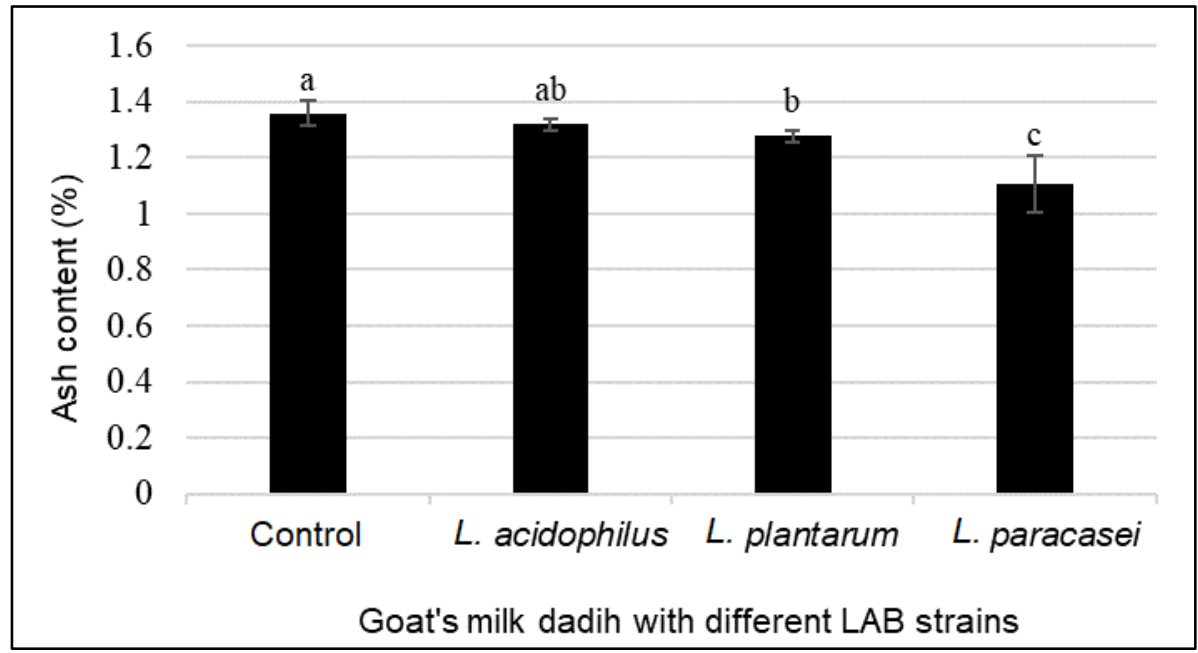

Figure 14. Mean value of ash content of goat's milk dadih with different strains of lactic acid bacteria Note: Mean value with different letters are significantly different $(p<0.05)$.

No significant differences ( $p>0.05$ ) in crude fat content were observed among the samples for cow's milk dadih and goat's milk dadih The fat content of the dadih was contributed primarily by the fat present in the milk. As seen in Figure 15 and Figure 16, the samples inoculated with LAB had lower fat content than the control samples. The data is supported by previous study where the supplemented goat's milk dadih with LAB had low fat content $(3.17 \%)$ than the control sample (3.93\%) [2]. This might be due to the utilisation of fat by $L A B$.

Fat content, as reported in this study, varied from 4.04 to $3.31 \%$ (cow's milk dadih) and 3.48 to $2.66 \%$ (goat's milk dadih). The findings were in agreement with Codex requirement where fermented milk products should have less than $10 \%$ of fat. Fat content was found to decrease as fermentation occurs. It might be due to the increased activity of lipolytic enzymes where the fat components were degraded into fatty acid and glycerol [24].

However, the fat of goat's milk is more digestible than that of cow's milk. It is because goat's milk has smaller and greater surface area of fat globules than cow's milk. Therefore, it is easier to be digested by lipases enzyme in the gut [9]. 


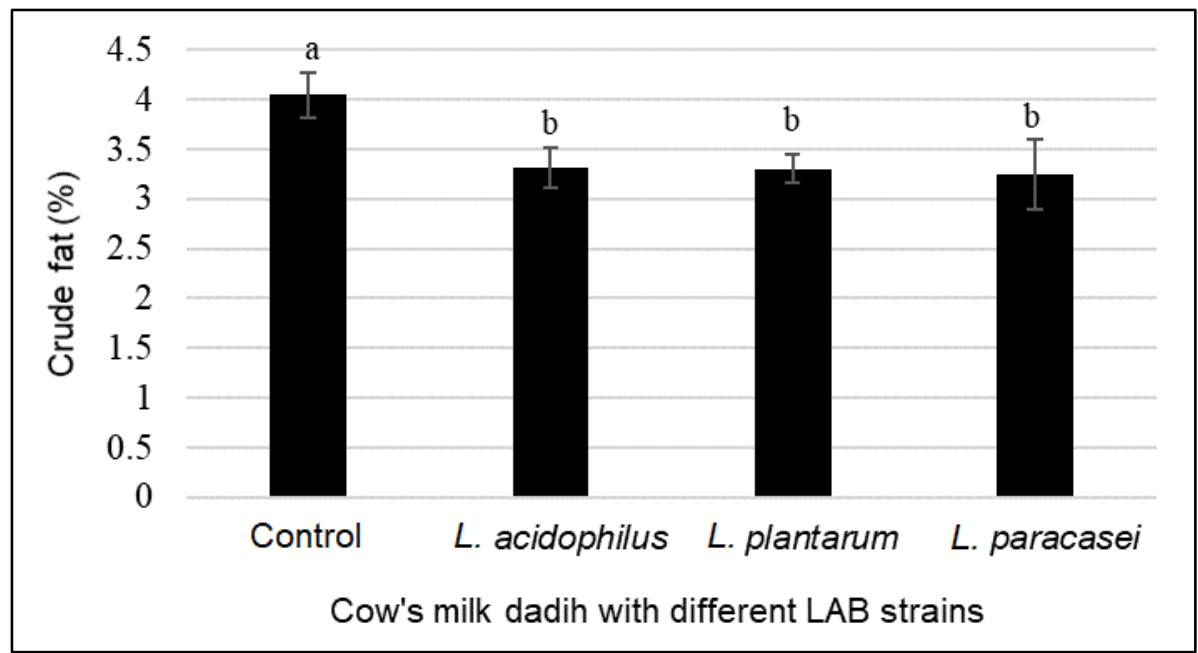

Figure 15. Mean value of crude fat content of cow's milk dadih with different strains of lactic acid bacteria Note: Mean value with different letters are significantly different $(p<0.05)$.

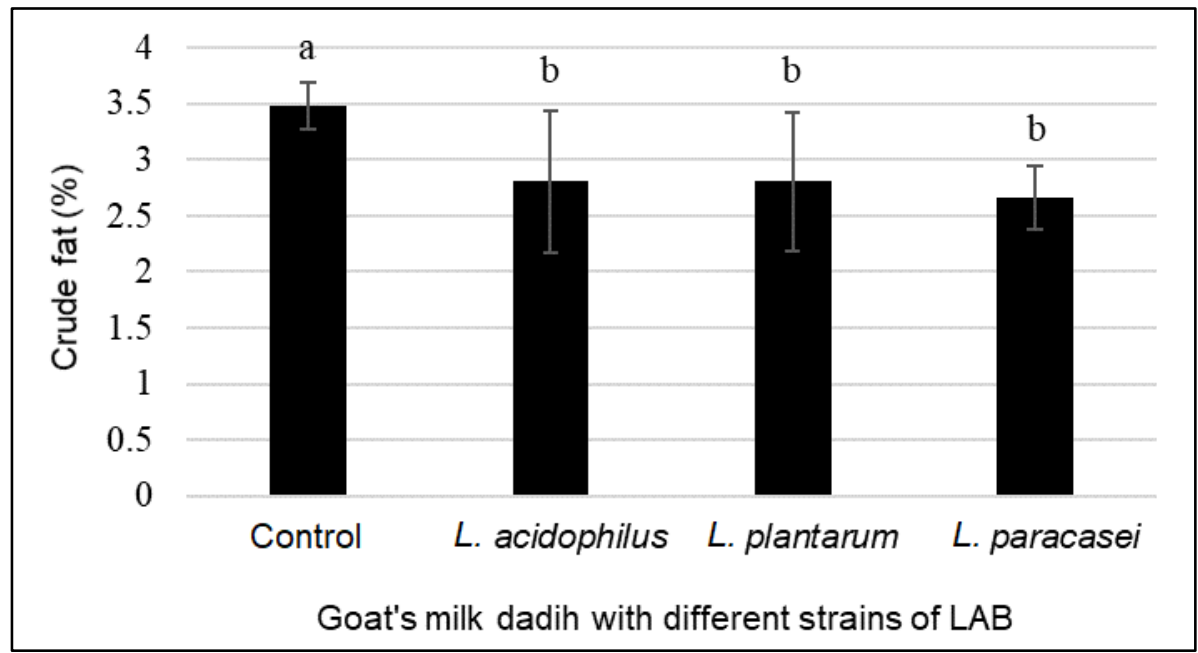

Figure 16. Mean value of crude fat content of goat's milk dadih with different strains of lactic acid bacteria Note: Mean value with different letters are significantly different $(p<0.05)$.

\section{Crude protein of Cultured Dadih}

Crude protein was determined by using Kjeldahl method. Figure 17 and Figure 18 show the crude protein content in the cow's milk dadih and goat milk dadih inoculated with different strains of LAB.

Both types of milk used for the production of dadih showed significant difference among the samples for each type of milk. Higher protein content was observed in control cow's milk dadih and goat's milk dadih $(4.04 \% \pm 0.22$ and $4.63 \% \pm 0.62$ respectively) while dadih inoculated with LAB had lower protein content. The findings were in agreement with Codex [16] requirement where the fermented milk products should have at least $2.7 \%$ of protein. 


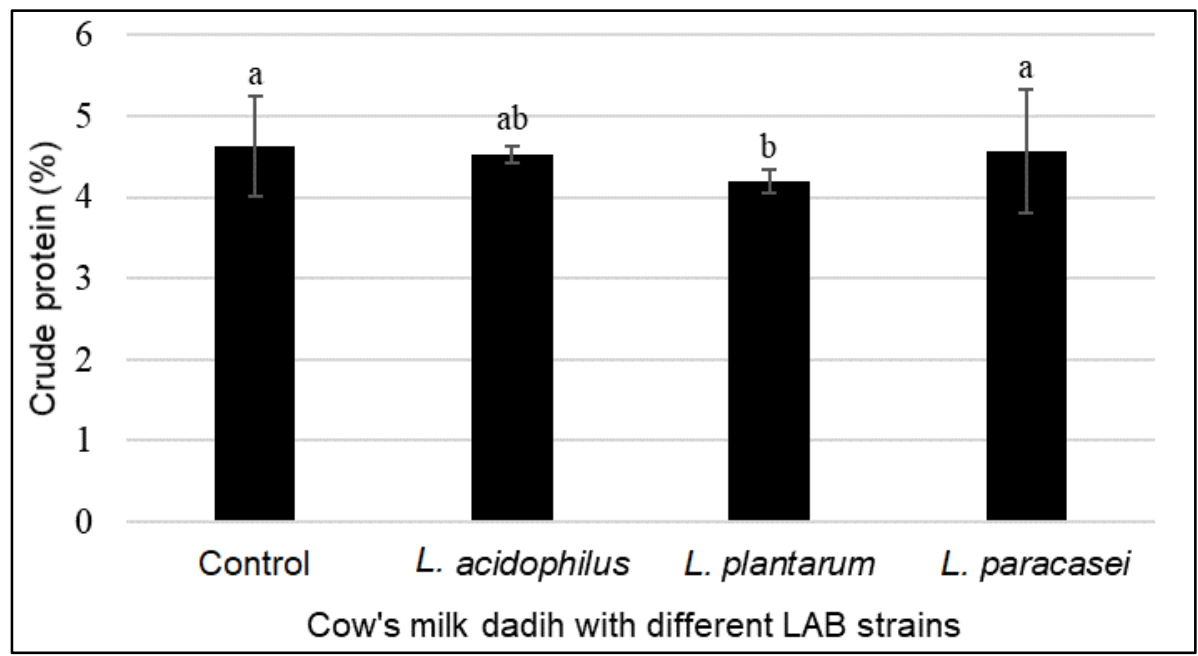

Figure 17. Mean value of crude protein content of cow's milk dadih with different strains of lactic acid bacteria

Note: Mean value with different letters are significantly different $(p<0.05)$.

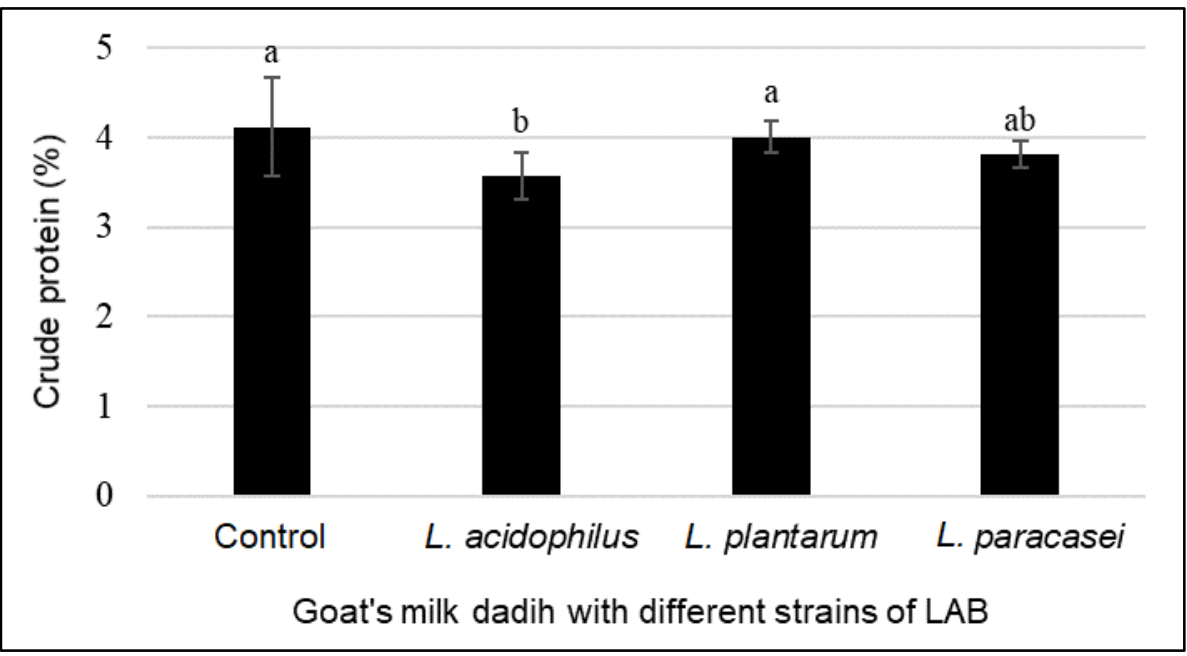

Figure 18. Mean value of crude protein content of goat's milk dadih with different strains of lactic acid bacteria

Note: Mean value with different letters are significantly different $(p<0.05)$.

The lower amount of protein in dadih inoculated with LAB than in control sample might be due to the presence of probiotic in the sample. The data is supported by previous study where the goat's milk dadih supplemented with L. acidophilus (3.17\%) has lower amount of protein than control sample (3.45\%) [2]. Previous findings explained that the presence of milk nutrients such as peptides and amino acids enhance the proliferation and growth of probiotic which uses these ingredients for supplementation and growth [2].

LAB utilizes milk proteins as their source of growth-stimulating amino acids. The milk proteins are hydrolyzed by LAB proteinases and peptidases into free amino groups and small peptides. Level of amino acids and peptides in milk are low. Therefore, the LAB depends on proteolytic system that allows for an efficient degradation of milk proteins. The presence of aminopeptidases is important for the release of amino acids for growth of microorganisms in the growth medium [25]. Besides, proteolytic system involved in casein utilization within LAB cell contributes to development of organoleptic properties of fermented milk products. 


\section{Total carbohydrate of Cultured Dadih}

Total carbohydrate of the dadih was determined by calculation where the total moisture, ash, protein and fat were subtracted from $100 \%$. Figures 19 and 20 show the mean of total carbohydrate for each sample.

Based on the result above, there was no significant difference ( $p>0.05)$ among the cow's milk dadih sample and also goat's milk sample. Generally, the carbohydrate content was contributed primarily by the dadih powder and sugar. The data for the amount of carbohydrate may not be precise because the determination of total carbohydrate by calculation may exclude or ignore the other nutrients contained in the sample. This method may not reflect the exact amount of carbohydrate contained in the dadih.

Unlike data illustrated in Figures 19 and 20, previous study reported that decreasing amount of carbohydrate of fermented soymilk was observed as fermentation occurs [24]. The condition can be explained by the activities of the LAB which utilize lactose, the major component of milk sugar and transform them into energy for their growth.

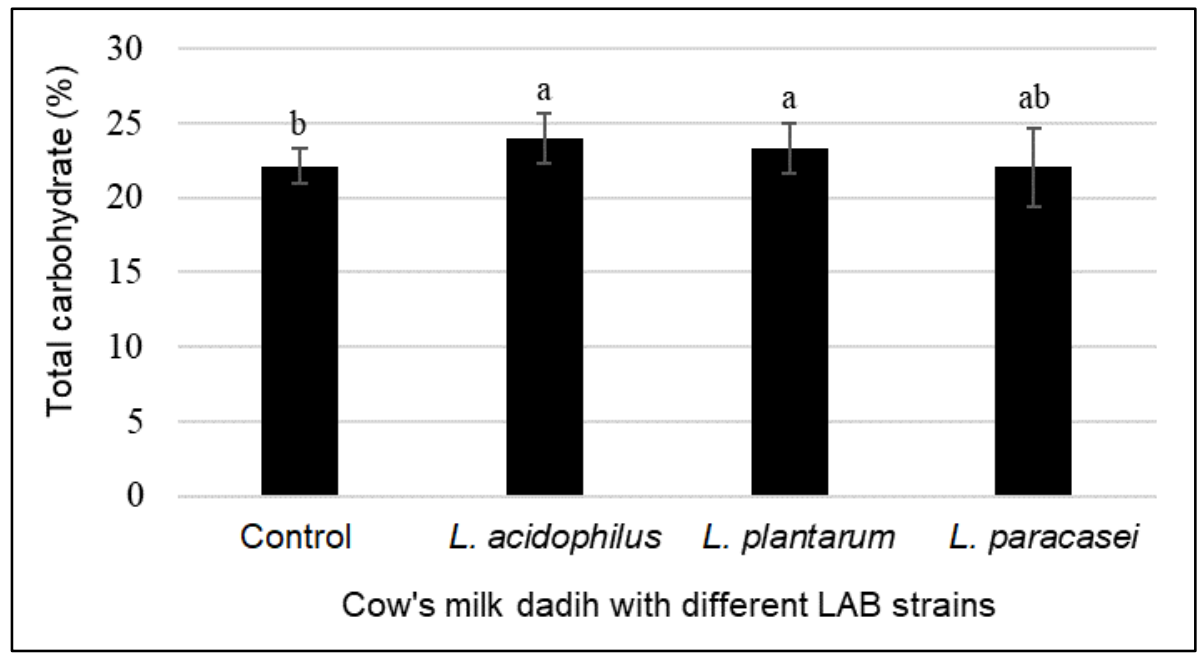

Figure 19. Mean value of total carbohydrate content of cow's milk dadih with different strains of lactic acid bacteria

Note: Mean value with different letters are significantly different $(p<0.05)$.

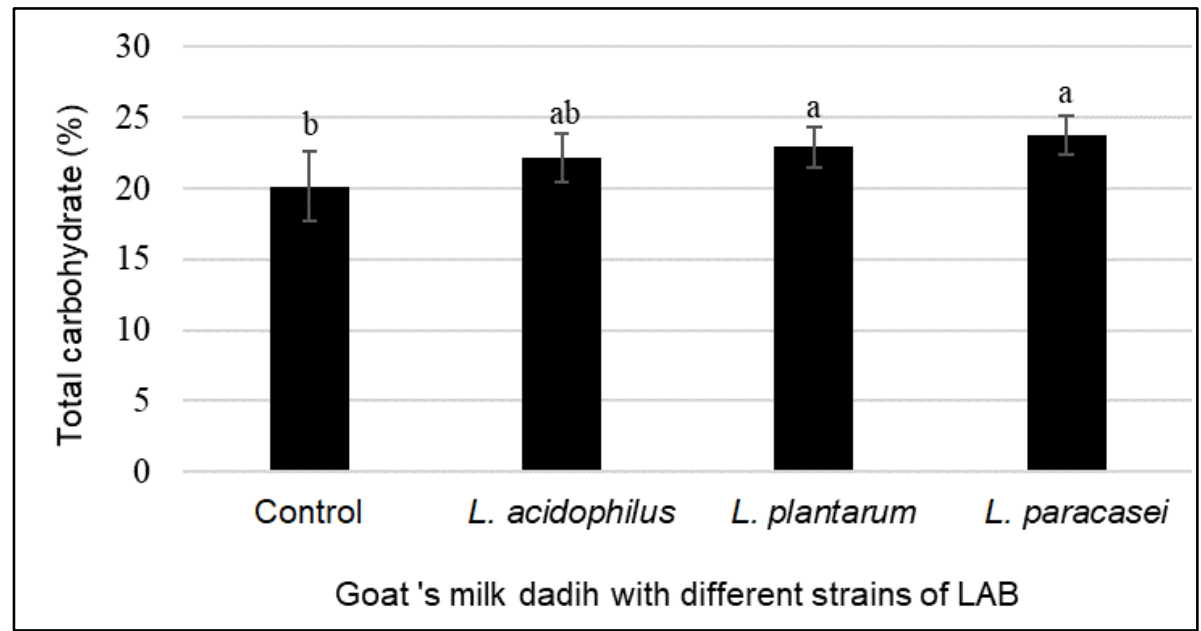

Figure 20. Mean value of total carbohydrate content of goat's milk dadih with different strains of lactic acid bacteria

Note: Mean value with different letters are significantly different $(p<0.05)$. 


\section{Conclusions}

The objectives of this study were to isolate the lactic acid bacteria from control dadih and to determine the microbiological and physicochemical properties of dadih using selected commercial strains of lactic acid bacteria. From this study, it can be concluded that several species of LAB can be found in the dadih. Three different LAB strains have been isolated from cow's milk dadih which are L. paracasei spp. paracasei, L. brevis and L. casei while only L. paracasei spp. paracasei was isolated from goat's milk dadih.

Besides that, the number of viable cells in general microbial load is similar with the viability of $L A B$ in $L A B$ count. Thus, the result indicates no undesirable growth of spoilage and pathogenic bacteria. Moreover, the addition of LAB into the dadih significantly affected $(p<0.05)$ both $\mathrm{pH}$ and lactic acid content in the dadih. The $\mathrm{pH}$ of cultured dadih was lower than control sample while the amount of lactic acid was higher than control sample. The inoculation of LAB into dadih reduced the degree of Brix or the total soluble solid in the sample. The hardness of the cultured dadih was also lower than the control sample.

The findings suggest that $L$. acidophilus is the most suitable starter culture to develop cultured dadih because this species of LAB shows significant effect on titratable acidity, total soluble solid and texture compared to L. paracasei and L. plantarum.

\section{Suggestions}

Nowadays, consumers are health-conscious and demand for "healthy" food products. This situation resulted in the increased consumption of functional foods. As functional food, the viability of probiotics in the products is very important. In order to claim the bacteria has probiotic properties, further study should be done on the stability of gut microbiome.

As cow's milk dadih and goat's milk dadih have diverse microflora, future study should be done on identification of other types of microorganisms instead of lactic acid bacteria species. This is important in order to know potential microorganisms that can lead to spoilage of the dadih.

Besides that, proteolysis in dadih can be studied. It is important to know whether the mode of proteolysis that occurs in the dadih is either contributed by LAB or naturally occurs in the dadih. Proteolysis in dadih can be studied by two approaches which are quantification of proteolytic changes and determination of proteolytic enzymes activity. Both of them have particular positive and negative aspects. Methods that can be used for detection of proteins degradation products are electrophoresis and the Kjeldahl method. They are reliable but time-consuming and inconvenient for manufacture use.

\section{Data availability}

The data that support the findings of this study are available from the corresponding author upon reasonable request.

\section{Conflicts of interest}

The authors declare that there is no conflict of interest regarding the publication of this paper.

\section{Funding statement}

Many thanks to Faculty of Fisheries and Food Science, UMT. 


\section{Acknowledgment}

The authors thank Malaysian Agricultural Research and Development Institute (MARDI) for accompanying during the project.

\section{References}

[1] J. M. Willey, L. Sherwood, and C. J. Woolverton, Prescott's microbiology, 8th ed. McGraw-Hill New York, 2011.

[2] S. Othman, A. Aziah, and R. J. I. F. R. J. Ahmad, "Effects of jackfruit puree supplementation on lactic acid bacteria (Lactobacillus acidophilus FTDC 1295) in terms of viability and chemical compositions of dadih," vol. 19, no. 4, 2012.

[3] L. Nuraida, "A review: Health promoting lactic acid bacteria in traditional Indonesian fermented foods," Food Science and Human Wellness, vol. 4, no. 2, pp. 47-55, 2015.

[4] T. Yuliana, F. Hayati, Y. Cahyana, T. Rialita, E. Mardawati, B.M. Harahap and R. Safitri. "Indigenous Bacteriocin of Lactic Acid Bacteria from" Dadih" a Fermented Buffalo Milk from West Sumatra, Indonesia as Chicken Meat Preservative," Pakistan Journal of Biological Sciences: PJBS, vol. 23, no. 12, pp. 1572-1580, 2020.

[5] K. Venema and I. Surono, "Microbiota composition of dadih-a traditional fermented buffalo milk of West Sumatra," Letters in applied microbiology, vol. 68, no. 3, pp. 234-240, 2019.

[6] BioMerieux. (2013). API. Available: http//moodle.univmontp2.fr/pluginfile.php/27441/mod_resource/content/1/ galerie\%201pi.pdf

[7] M. N. Lani, S. Ahmad, R. Ibrahim, R. Alias, and Z. J. I. J. E. S. Hassan, "Evaluation on chemical analysis and microbiological quality of partially cooked-frozen of Malaysian heritage food ('Satar')," vol. 3, no. 9, pp. 71-77, 2014.

[8] A. Aramide, S. Abiose, and A. J. A. J. o. F. S. Adeniran, "Microbial evaluation of probiotic beverage from roselle extract," vol. 3, no. 12, pp. 385-392, 2009.

[9] S. Chye, R. Ahmad, and N. A. J. I. F. R. J. Aziah, "Studies on the physicochemical and sensory characteristics of goat's milk dadih incorporated with tropical-fruit purees," vol. 19, no. 4, p. 1387, 2012.

[10] A. o. O. A. C. (AOAC), Official methods of analysis, 17th ed. Gaithersburg, MD: Association of Official Analytical Chemists, 2000.

[11] G. S. de Giori and E. M. Hébert, "Methods to determine proteolytic activity of lactic acid bacteria," in Food microbiology protocols. , vol. 14: Humana Press 2001, pp. 197-202.

[12] N. Büchl and H. Seiler, "Yeast and Molds/Yeasts in Milk and Dairy Products," pp. 744-753, 2011.

[13] L. Nora and G. J. I. R. F. B. Bettache, "Antifungal activity of newly isolates of lactic acid bacteria," no. 13, pp. 80-88, 2013.

[14] B. Adolphi, K. E. Scholz-Ahrens, M. de Vrese, Y. Açil, C. Laue, and J. J. E. j. o. n. Schrezenmeir, "Short-term effect of bedtime consumption of fermented milk supplemented with calcium, inulin-type fructans and caseinphosphopeptides on bone metabolism in healthy, postmenopausal women," vol. 48, no. 1, pp. 45-53, 2009.

[15] A. Gesinde, O. Oyawoye, and A. Adebisi, "Comparative studies on the quality and quantity of soymilk from different varieties of soybean," Pakistan Journal of Nutrition, no. 7, pp. 157-160, 2008.

[16] Codex Standard for Fermented Milks and FOA. (2003). Available: Available from: http://www.bing.com/ cr?IG=0CEEB93EEF8E4AB5AAB07B7E21E43A1F\&CID=02924D7E1A8B68D4181246041B2469C4\&rd=1\&h =Kjol8YS68Q38cpgtcudQItFmAWDh2FCPB1NOhuy6T6U\&v=1\&r=http\%3a\%2f\%2fwww.fao.org\%2finput\%2fd ownload\%2fstandards\%2f400\%2fCXS_243e.pdf\&p=DevEx,5067.1

[17] P. S. Murano, Understanding food science and technology (no. $664.00688 \mathrm{M} 931 \mathrm{u}$ Ej. 1022147$)$. Toronto, ON: Nelson Education Ltd, 2011.

[18] M. El-Salam and S. El-Shibiny, "A comprehensive review on the composition and properties of buffalo milk," Dairy Sci. Technol., vol. 91, no. 6, pp. 663- 690, 2011.

[19] N. N. Potter and J. H. Hotchkiss, Food science, 5th ed. Springer Science \& Business Media, 2012.

[20] J. M. Kongo, Lactic acid bacteria as starter-cultures for cheese processing: past, present and future developments. InTech, 2013, pp. 1-22.

[21] B. P. Ismail, "Ash content determination," in Food Analysis Laboratory Manual: Springer, 2017, pp. 117-119.

[22] Y. W. Park, G. F. Haenlein, and W. L. Wendorff, Y. W. P. G. F. W. Haenlein, Ed. Handbook of milk of nonbovine mammals. Blackwell Publishing Professional, Ames, IA, 2006.

[23] P. Ribéreau-Gayon, D. Dubourdieu, B. Donèche, and A. Lonvaud, Handbook of enology, Volume 1: The microbiology of wine and vinifications. John Wiley \& Sons, 2006.

[24] A. Obadina, O. Akinola, T. Shittu, and H. J. N. F. J. Bakare, "Effect of natural fermentation on the chemical and nutritional composition of fermented soymilk nono," vol. 31, no. 2, pp. 91-97, 2013.

[25] O. N. Donkor, A. Henriksson, T. Vasiljevic, and N. P. J. L. L. Shah, "Proteolytic activity of dairy lactic acid bacteria and probiotics as determinant of growth and in vitro angiotensin-converting enzyme inhibitory activity in fermented milk," vol. 87, no. 1, pp. 21-38, 2007. 